\title{
Airborne transmission of pathogen-laden expiratory droplets in open outdoor space
}

Article

Accepted Version

Creative Commons: Attribution-Noncommercial-No Derivative Works 4.0

Yang, X., Yang, H., Ou, C., Luo, Z. ORCID:

https://orcid.org/0000-0002-2082-3958 and Hang, J. (2021)

Airborne transmission of pathogen-laden expiratory droplets in open outdoor space. Science of the Total Environment, 773. 145537. ISSN 0048-9697 doi:

https://doi.org/10.1016/j.scitotenv.2021.145537 Available at https://centaur.reading.ac.uk/95854/

It is advisable to refer to the publisher's version if you intend to cite from the work. See Guidance on citing.

To link to this article DOI: http://dx.doi.org/10.1016/j.scitotenv.2021.145537

Publisher: Elsevier

All outputs in CentAUR are protected by Intellectual Property Rights law, including copyright law. Copyright and IPR is retained by the creators or other copyright holders. Terms and conditions for use of this material are defined in the End User Agreement.

\section{www.reading.ac.uk/centaur}

\section{CentAUR}


Central Archive at the University of Reading

Reading's research outputs online 


\section{Highlights}

$2>$ Droplet evaporation and transport in open outdoor space are studied by CFD.

$3>$ Impacts of relative humidity $(R H=35 \%, 95 \%)$ and droplet size $(10-100 \mu \mathrm{m})$ are

4 tested.

$5>$ Thermal body plume is destroyed as $U_{\text {ref }}=3 \mathrm{~m} / \mathrm{s}$ while significant as $U_{r e f}=0.2 \mathrm{~m} / \mathrm{s}$.

$6>$ Social distances $(D=0.5-5 \mathrm{~m})$ for two face-to-face patients downwind are studied.

$7>$ Exposure risk exponentially reduces with $D$ at $U_{\text {ref }}=3 \mathrm{~m} / \mathrm{s}$ but exceeds that at $0.2 \mathrm{~m} / \mathrm{s}$.

8

9 


\section{Graphical abstract}

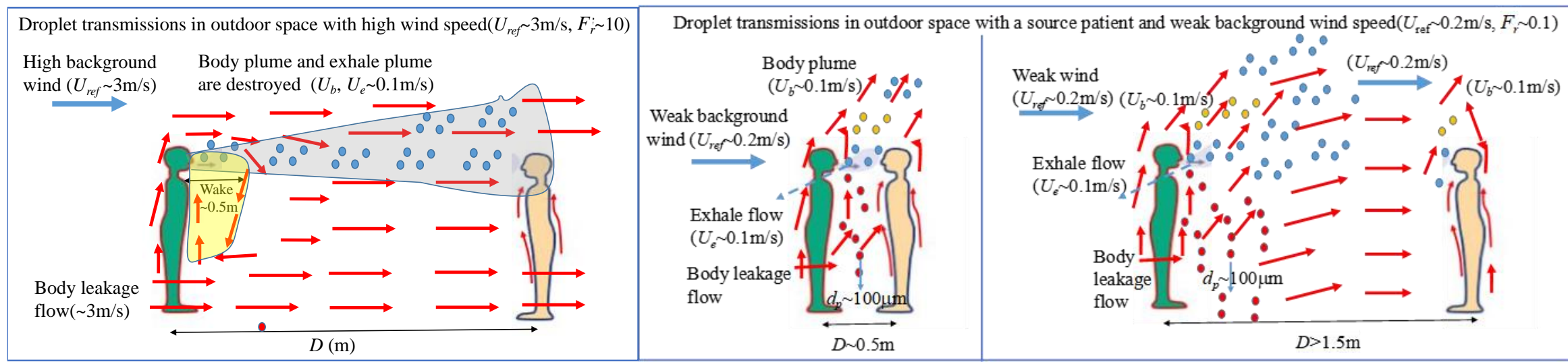

Highest exposure risk

High exposure risk

Low exposure risk 


\title{
$\underline{\text { To be submitted to Science of the Total Environment } 2021}$
}

\section{Airborne transmission of pathogen-laden expiratory droplets in open outdoor space}

\author{
Xia Yang ${ }^{1,2,3 \#}$, Hongyu Yang ${ }^{1,2,3}$, Cuiyun Ou${ }^{1,2,3,4 \#}$, Zhiwen Luo ${ }^{5^{*}}$, Jian Hang ${ }^{1,2,3 *}$
}

${ }^{1}$ School of Atmospheric Sciences, Guangdong Province Key Laboratory for Climate Change and Natural Disaster Studies, Sun Yatsen University, Zhuhai 519082, P.R. China

${ }^{2}$ Southern Marine Science and Engineering Guangdong Laboratory (Zhuhai), Zhuhai, China

${ }^{3}$ Guangdong Provincial Field Observation and Research Station for Climate Environment and Air Quality Change in the Pearl River Estuary, 510275 Guangzhou, China

${ }^{4}$ State Key Laboratory of Green Building in Western China, Xian University of Architecture \& Technology, 710055 Xi'an, China ${ }^{5}$ School of the Built Environment, University of Reading, Reading, UK

${ }^{\#}$ These authors contribute equally as the first author.

*Corresponding author: Zhiwen Luo, Jian Hang

Tel: $+447450984193 ;+86-13710248541$

E-mail address: z.luo@,reading.ac.uk; hangj3@mail.sysu.edu.cn

\section{Abstract}

Virus-laden droplets dispersion may induce transmissions of respiratory infectious diseases. Existing research 
mainly focuses on indoor droplet dispersion, but the mechanism of its dispersion and exposure in outdoor environment is unclear. By conducting CFD simulations, this paper investigates the evaporation and transport of solid-liquid droplets in an open outdoor environment. Droplet initial sizes $\left(d_{p}=10 \mu \mathrm{m}, 50 \mu \mathrm{m}, 100 \mu \mathrm{m}\right)$, background relative humidity $(R H=35 \%, 95 \%)$, background wind speed $\left(U_{r e f}=3 \mathrm{~m} / \mathrm{s}, 0.2 \mathrm{~m} / \mathrm{s}\right)$ and social distances between two people $(D=0.5 \mathrm{~m}, 1 \mathrm{~m}, 1.5 \mathrm{~m}, 3 \mathrm{~m}, 5 \mathrm{~m})$ are investigated.

Results show that thermal body plume is destroyed when the background wind speed is $3 \mathrm{~m} / \mathrm{s}$ (Froude number $\left.F_{r} \sim 10\right)$. The inhalation fraction $(I F)$ of susceptible person decreases exponentially when the social distance $(D)$ increases from $0.5 \mathrm{~m}$ to $5 \mathrm{~m}$. The exponential decay rate of inhalation fraction $(b)$ ranges between 0.93 and 1.06 $\left(I F=I F_{0} e^{-b(D-0.5)}\right)$ determined by the droplet initial diameter and relative humidity. Under weak background wind $\left(U_{r e f}=0.2 \mathrm{~m} / \mathrm{s}, F_{r} \sim 0.01\right)$, the upward thermal body plume significantly influences droplet dispersion, which is similar with that in indoor space. Droplets in the initial sizes of $10 \mu \mathrm{m}$ and $50 \mu \mathrm{m}$ disperse upwards while most of $100 \mu \mathrm{m}$ droplets fall down to the ground due to large gravity force. Interestingly, the deposition fraction on susceptible person is ten times higher at $U_{r e f}=3 \mathrm{~m} / \mathrm{s}$ than that at $U_{r e f}=0.2 \mathrm{~m} / \mathrm{s}$. Thus, a high outdoor wind speed does not necessarily lead to a smaller exposure risk if the susceptible person locating at the downwind region of the infected person, and people in outdoors are suggested to not only keep distance of greater than $1.5 \mathrm{~m}$ from each other but also stand with considerable angles from the prevailing wind direction.

Keywords: computational fluid dynamic (CFD) simulation; droplet dispersion; relative humidity; social distance; outdoor environment 


\section{Introduction}

Respiratory infectious diseases remain a significant threat to human's life. Since December 2019, the novel coronavirus (SARS-CoV-2) has caused global pandemic. By December $19^{\text {th }}, 2020$, novel coronavirus pneumonia infections in the world have exceeded 76 million (WHO, 2020a). The main reason for the prevalence of respiratory infections is the interpersonal transmission of droplets/aerosols/particles, which carry viral RNA (Asadi et al. 2020; Kutter et al., 2018; Lindsley et al., 2010).

Three recognized routes of respiratory disease transmission are reported: contact, droplet transmission and airborne transmission (aerosol) (Gao et al., 2021; Liu et al., 2017; Qian and Li, 2010). Contact route represents direct or indirect touch with the infected person; droplet transmission is dominant when the susceptible persons are close to infected ones (Liu et al., 2017; Xie et al., 2007 and 2009); while the fine droplet is favorable for relatively longdistance airborne transmission. Through respiratory activities, the infected person releases droplets containing pathogens which are the media of infection. SARS-CoV-1 and SARS-CoV-2 are demonstrated to remain viable in aerosols with a half-life of about $1 \mathrm{~h}$ (Doremalen et al., 2020). Therefore, droplet/aerosol can spread in many indoor or outdoor environments and people may get infected unconsciously.

There are numerous studies on indoor ventilation and droplet dispersion since the outbreak of SARS in 2003 (Gupta et al., 2012; Hang et al., 2015; Li et al., 2007 and 2020; Mui et al., 2009; Wang et al., 2020a; Yang et al., 2020b; Zhang and Li, 2012). There are also studies on the risk of inter-unit and cross-unit transmissions between different floors and adjacent buildings in urban street (e.g. Liu et al., 2011a and 2011b; Yu et al., 2004).

However, most outdoor ventilation and pollutant dispersion studies emphasized the ventilation evaluation (e.g. Chen et al., 2017; Yang et al., 2020c; Zhang et al., 2020c) and the dispersion of gaseous vehicular pollutants (He et 
al., 2017; Liu et al., 2015; Yang et al., 2020a; Zhang et al., 2019 and 2020a), the particulate matter (Habilomatis and Chaloulakou, 2015; Scungio et al., 2018; Tung et al., 2021; Yao et al., 2020), or hazardous chemical gases released outdoors (Bartzis et al., 2015). Droplets suspended in air may evaporate meanwhile move under the interaction of wind-driven drag forces and gravity forces etc. Investigations on outdoor droplet evaporation and dispersion as well as their exposure risk are still rare so far. Similar with the flow and dispersion processes indoor (e.g. Hang et al., 2014 and 2015; Zhang and Li, 2012), outdoor airflows and dispersion processes are also determined by the coupling effect of dynamic force and thermal buoyancy force (e.g. Antoniou et al., 2019; Chatterjee et al., 2019; Liu et al., 2020; Zhang et al., 2020a). Although there is consensus on the low risk of outdoor transmission for COVID-19, the full picture of its underlying physics remains to be studied. There is increasing evidence that outdoor transmission could occur, for instance in a seafood market (Zhang et al., 2020b).

The WHO suggests that, for indoor environments, a distance of $1 \mathrm{~m}$ or more between each other is required to reduce the risk of infection (WHO, 2020b). The Centers for Disease Control and Prevention recommends a 6 feet physical distancing rule (CDC, 2020). There are also many studies on the airborne transmission within the certain social distance in indoor environments (Li et al, 2020; Liu et al., 2017; Shen et al., 2020). Identifying an effective social distance is of great importance to avoid transmission of infectious diseases such as SARS and SARS-CoV-2 (Kissler et al., 2020; Gao et al., 2021).

Recently, Feng et al. (2020) investigated the outdoor droplet dispersion from patient coughing (i.e. pulse exhale flow $\sim 10 \mathrm{~m} / \mathrm{s}$ ) under two social distance of $1.83 \mathrm{~m}$ and $3.05 \mathrm{~m}$. According to their simulated statistics, the outdoor social distance longer than $1.83 \mathrm{~m}$ needs to be considered. There is increasing evidence showing the infection transmission from the asymptomatic patients via normal respiratory activities such as breathing and speaking 
(Doremalen et al., 2020; Li et al., 2020). Hence, it is worth further investigating outdoor droplet transmissions and exposure risks under more realistic conditions, e.g. social distances, outdoor wind conditions, ambient relative humidity, and the interactions among them. For outdoor droplet transmissions, our research aims to answer the following questions: whether there is effective social distancing threshold similar with indoor environment? Is it possible to provide the useful outdoor social distance guideline?

Droplet initial size is the key factor in droplet diffusion (Bourouiba, 2020; Gao et al., 2021). Large droplets may fall first and experience slow dilution due to the relatively large gravity. Small droplets are easily affected by the surrounding airflow and spread more widely and farther. Droplets are composed of liquid and solid, and only solid component remains after the liquid evaporates. Their evaporation and dispersion process are influenced by the ambient relative humidity and accompanied with the change of droplet gravity and buoyancy (Wei and Li, 2015; Xie et al., 2007; Yang et al., 2020b). Relative humidity which robust associate with the ambient temperature has been confirmed to greatly influence the droplet motion in ambient air (Dombrovsky et al., 2020; Hasan et al., 2021; Marr et al., 2019; Zhao et al., 2012). On the other hand, in outdoor environments, background wind speed may significantly influence droplets evaporation time and dispersion range, while the relevant studies are still limited so far.

To address these research gaps, we investigate the combined effect of two ambient wind speeds $\left(U_{\text {ref }}=3\right.$ and $0.2 \mathrm{~m} / \mathrm{s})$, relative humidity $(R H=35 \%, 95 \%)$ and initial droplet size $\left(d_{p}=10 \mu \mathrm{m}, 50 \mu \mathrm{m}\right.$ and $\left.100 \mu \mathrm{m}\right)$, various social distances between two standing persons $(D=0.5 \mathrm{~m}, 1 \mathrm{~m}, 1.5 \mathrm{~m}, 3 \mathrm{~m}, 5 \mathrm{~m})$ on droplet transmissions and exposure risk in an open outdoor space. We consider the worst case that the susceptible person is just located in the downwind regions of the infected person. 


\section{Methodology}

\subsection{Physical models}

As depicted in Fig. 1a, we have built a simulation domain to mimic outdoor open environment. Two thermal manikins with the height of $H=1.68 \mathrm{~m}$ are positioned in the center of the domain, with source manikin in the upstream and susceptible manikin in the downstream. The simulation domain is $L_{x} \times L_{y} \times L_{z}=(24.17 H+D) \times 24.14 H \times 5.95 H(D$ is the distance between tiptoes of source and susceptible manikin). The domain is large enough to avoid the boundary effects of domain lateral side and domain top according to the guideline by Franke et al. (2011) and Tominaga et al. (2008) for outdoor wind CFD simulation. Validation study have been carried by comparing the simulation results to experimental data, which is illustrated in Section3. The validation results prove that present CFD simulations are effective and grid size of $5 \mathrm{~cm}$ can be adopted after grid independence test. Therefore, in the following investigating cases, the grid size close to manikins (areas with the dimension of $4 \mathrm{~m} \times 4 \mathrm{~m} \times 4 \mathrm{~m}$ ) is $0.05-0.1 \mathrm{~m}$ and the grid expansion ratio is less than 1.3 in the outer region (Fig. 1b). Detailed grid arrangement for manikins' surfaces is presented in Fig. $1 \mathrm{~b}$ and grids near mouse, nostril, head, neck and limbs are refined (Yang et al., 2020b). The total number of grids is 1.32 to 6.88 million.

The fate of droplets, including those deposited on the different surfaces (Fig. 1c) of, and inhaled by the susceptible person, are calculated to quantify the susceptible manikin's infection risk, which can effectively prevent and control the spread of respiratory infectious diseases. Fig. 1d shows the flowchart and brief process of this study including the validation, CFD investigating cases and the perspective of discussion.

\subsection{Description for airflow modeling}

The Reynolds-Averaged Navier-Stokes (RANS) turbulence approaches are used for turbulent flow simulation 
due to its cost-effectiveness in comparison with Large Eddy Simulation (LES) models. The standard $k$ - $\varepsilon$ turbulence model is one of the most widely-adopted models, and is employed in this study. The governing equations and the turbulence parameters of standard $k-\varepsilon$ model can be found in the literature (e.g. Chen, 1995; Tung et al., 2009). Thus, ANSYS FLUENT (ANSYS Inc, version 15.0), together with the standard $k$ - $\varepsilon$ turbulence model, is applied to simulate the steady-state isothermal and non-isothermal airflows around human bodies.

For the domain inlet, the velocity profile with a power-law exponent of 0.16 (see Eq. (1)) is used to provide an inflow boundary condition in the upstream free flow. It corresponds to a neutrally stratified atmospheric boundary layer (ABL) with a full-scale surface roughness of $z_{0}=0.1 \mathrm{~m}$ (Irwin, 1979; Lien and Yee, 2004; Lin et al., 2014). This wind profile is fitted by the experimental data from Brown et al. (2001) together with turbulence kinetic energy $(k)$ and its dissipation rate $(\varepsilon)$ which are defined as below:

$$
\begin{aligned}
& u_{0}(z)=U_{\text {ref }}\left(\frac{z}{z_{\text {ref }}}\right)^{0.16} \\
& k(z)=u_{*}^{2} / \sqrt{C_{\mu}} \\
& \varepsilon(z)=C_{\mu}^{\frac{3}{4}} k^{\frac{3}{2}}(\kappa z)
\end{aligned}
$$

where $U_{r e f}=3 \mathrm{~m} / \mathrm{s}$ or $0.2 \mathrm{~m} / \mathrm{s}$ is the velocity at the reference height (here $z_{r e f}=30 \mathrm{~m}$ ); $C_{\mu}$ is a constant of 0.09 ; Karman constant $\kappa$ is 0.41 .

The Boussinesq approximation model is applied to consider the thermal buoyancy effect. The manikin's body surface area is $1.46 \mathrm{~m}^{2}$, and the heat flux from the standing body surface is defined as $58 \mathrm{~W} / \mathrm{m}^{2}$, which is the same with the standing nurse in Hang et al. (2014) and Tung et al. (2009). As depicted in Fig. 1a, the steady breathing flow is assumed to be exhaled from the nostril of source patient and inhaled from the nostril of susceptible person (Zhao et al., 2005). The steady breathing flow is perpendicular to the nostril plane which is $3.3 \mathrm{~cm}^{2}$ (Fig. 1a), with the 
temperature of $308 \mathrm{~K}$ and mass flow rate of $1.225 \times 10^{-4} \mathrm{~kg} / \mathrm{s}$ (Hang et al., 2014; Liu et al., 2010; Qian and Li, 2010),

Froude number $\left(F_{r}\right)$ can be used to represent the relative importance of buoyancy and wind shear $\left(F_{r}=T_{r e f} U_{H}^{2} /(\mathrm{g} H \Delta T)\right.$, where $\Delta T$ is the temperature difference between background air and body surface, $U_{H}$ is the velocity in the height of $H$ ) (Nazarian and Kleissl, 2016). The background air temperature at the domain inlet is $T_{\text {ref }}=300 \mathrm{~K}$. In this work, two different conditions are considered: $F_{r} \sim 10$ (much great than 1 ) when $U_{r e f}=3 \mathrm{~m} / \mathrm{s}$ $(U \approx 1.9 \mathrm{~m} / \mathrm{s}, \Delta T \approx 5 \mathrm{~K})$ and wind dominates; $F_{r} \sim 0.01$ (much less than 1 ) when $U_{r e f}=0.2 \mathrm{~m} / \mathrm{s}\left(U_{H} \approx 0.1 \mathrm{~m} / \mathrm{s}, \Delta T \approx 10 \mathrm{~K}\right)$ and buoyancy dominates.

The conservation governing equations were discretized by a finite volume method (FVM). Pressure and velocity are coupled by the SIMPLE algorithm. The second-order upwind scheme is used to discretize the convection and diffusion-convection terms in all governing equations. Except for the case when $F_{r}$ is small (i.e. reference wind velocity at $z_{\text {ref }}=30 \mathrm{~m}$ is $0.2 \mathrm{~m} / \mathrm{s}$ ), the turbulent dissipation is resolved by the first-order upwind scheme to attain better numerical convergence. Convergence is considered to be obtained when residuals for $x, y$ and $z$ momentum, $k, \varepsilon$ and continuity are stably below $10^{-5}$ for the case of $U_{\text {ref }}=3 \mathrm{~m} / \mathrm{s}$ and below $10^{-4}$ for the case of $U_{\text {ref }}=0.2 \mathrm{~m} / \mathrm{s}$.

\subsection{Description of droplet dispersion modeling}

Droplets are released continuously from the patient's nostril at a rate of 46 droplets per time step $(\Delta \mathrm{t}=0.01 \mathrm{~s})$ after steady solutions for the non-isothermal airflow have been obtained. The Lagrangian method is used to solve the motion equation of a single droplet according to Newton's second law:

$$
\frac{\mathrm{d} u_{\mathrm{pi}}}{\mathrm{dt}}=\sum F_{i}=F_{\text {drag }, i}+F_{g, i}+F_{a, i}
$$

where $u_{p i}$ is the droplet velocity $(\mathrm{m} / \mathrm{s})$, and $\sum F_{i}$ is the sum of all external forces on the droplet (per unit droplet mass, $\mathrm{m} / \mathrm{s}^{2}$ ) in the $i$ direction. The external forces consist of the drag force $F_{d r a g, i}$, the gravity $F_{g, i}$ and the additional 
forces $F_{a, i} . F_{\text {drag, } i}$ is the drag force on the droplet (per unit droplet mass, $\mathrm{m} / \mathrm{s}^{2}$ ) in the $i$ direction given by:

$$
F_{\text {drag }, i}=f_{D} / \tau_{p}\left(u_{i}-u_{p, i}\right)
$$

where $u_{i}$ is the air velocity $(\mathrm{m} / \mathrm{s}) ; f_{D}$ is the Stoke's drag modification function for large aerosol Reynolds number $\left(R e_{p}\right)$ and $\tau_{p}$ is the aerosol characteristic response time (s), which are defined as:

$$
\begin{aligned}
& f_{D}\left(R e_{p}\right)=1+0.15 R e_{p}^{0.687} \\
& \tau_{p}=\rho_{p} d_{p}^{2} C_{c} /(18 \mu)
\end{aligned}
$$

where $\rho_{p}$ is the droplet density $\left(\mathrm{kg} \cdot \mathrm{m}^{-3}\right) ; d_{p}$ is the droplet diameter $(\mathrm{m})$ and $\mu$ is the turbulent viscosity $\left(\mathrm{kg} \cdot \mathrm{m}^{-1} \cdot \mathrm{s}^{-}\right.$ $\left.{ }^{1}\right) ; C_{c}$ is the Cunningham correction to Stokes drag law defined as:

$$
C_{c}=1+2 \lambda\left(1.257+0.4 e^{-\left(1.1 d_{p} / 2 \lambda\right)} / d_{p}\right.
$$

where $\lambda$ is the molecular mean free path of air.

$F_{g, i}$ is the gravity given by:

$$
F_{g, i}=g_{i}\left(\rho_{p}-\rho\right) / \rho_{p}
$$

where $\rho$ is the air density; $g_{i}$ is the acceleration of gravity in the $i$ direction. $F_{a, i}$ is the additional force which include the pressure force, virtual mass force, Basset force, Brownian force and Saffman's lift force (Qian and Li, 2010; Zhao et al., 2004; Zhang and Li, 2012). Among them, we only consider Brownian force and Saffman's lift force as they may play an important role in sub-micron droplets' motion near walls while the other forces are sufficiently small (Zhao et al., 2004). Some assumptions are considered to simplify the calculation: (a) the droplets are considered to be ideal sphere shape; (b) the influence of droplets on airflow is neglected; (c) no droplet coagulates in its deposition process.

The droplet consists of $90 \%$ liquid (water, which density is $1000 \mathrm{~kg} / \mathrm{m}^{3}$ ) and $10 \%$ solid elements (sodium chloride, 
which density is $2170 \mathrm{~kg} / \mathrm{m}^{3}$ ) (Potter et al., 1963; Yang et al., 2020b), whose density follows the volume weighted mixing law. The default diffusion-controlled vaporization model is applied to calculate the evaporation of the droplets (ANSYS Inc, version 15.0), and their vaporization rate is defined as:

$$
N_{i}=k_{c}\left(C_{i, s}-C_{i, s r}\right)
$$

where $N_{i}\left(\mathrm{~kg} \cdot \mathrm{mol} \cdot \mathrm{m}^{-2} \cdot \mathrm{s}^{-1}\right)$ is the molar flux of vapor and related to the gradient of the vapor concentration between the droplet surface $C_{i, S}$ and the surrounding air $C_{i, s r}\left(\mathrm{~kg} \cdot \mathrm{mol} \cdot \mathrm{m}^{-3}\right)$ and can be obtained via the ideal gas relationship and molar fractions of water vapor; $k_{c}(\mathrm{~m} / \mathrm{s})$ is the mass transfer coefficient that can be obtained using Sherwood relationship; Droplet evaporation is influenced by $R H$ in terms of $C_{i, s r}$ in Eq. (10).

For boundary conditions of droplet dispersion, the trap condition is applied at human body surfaces. It is assumed that droplets are deposited when they touch the wall surfaces and the trajectory calculation is terminated. Escape condition is applied to the inlet, outlet, lateral boundaries and roof of the domain.

After 210 seconds of droplet release, we use the total release number $\left(N_{\text {total }}\right)$ of the source patient to normalize the deposition number $\left(N_{\text {deposited }}\right)$ and inhaling volume $\left(N_{\text {inhaled }}\right)$. Deposition fraction $(D F)$ and inhalation fraction $(I F)$ are calculated as below:

$$
\begin{aligned}
& D F=N_{\text {deposited }} / N_{\text {total }} \\
& I F=N_{\text {inhaled }} / N_{\text {total }}
\end{aligned}
$$

The fraction of droplet deposited on human face $\left(D F_{\text {face }}\right)$, front $\left(D F_{\text {front }}\right)$ and legs $\left(D F_{\text {legs }}\right)$ are also defined by Eq. (11) and Eq. (12), where $N_{\text {deposited }}$ is the droplet number deposited on different part of susceptible person according to Fig. 1c.

\section{CFD validation study}

The experimental data of droplet dispersion in an isolation room (Yin et al. 2009) was used to validate CFD 
simulation (Ansys Inc 15.0). The experiment was carried out in an isolation room to investigate the performance of mixing ventilation and displace ventilation (Fig. 2). The CFD setup were consistent with the scenario of displace ventilation, where air supply rate was 114 cubic feet per minute $(\mathrm{CFM})$ with the temperature of $19.5^{\circ} \mathrm{C}$, and the bathroom and main exhaust rates were $36 \mathrm{CFM}$ and 78CFM respectively. The patient, visitor, TV and equipment respectively generated $106 \mathrm{~W}, 110 \mathrm{~W}, 24 \mathrm{~W}$ and $36 \mathrm{~W}$ of heat. $1 \mu \mathrm{m}$ particle was released from the patient mouth. The mesh was generated with the maximum grid size of $5 \mathrm{~cm}$ (fine grid, total tetrahedral cells of 1.8 million) and $10 \mathrm{~cm}$ (coarse grid, total tetrahedral cells of 0.38 million). More details can be found in Yin et al. (2009).

Vertical profiles of velocity and temperature were measured at heights of $0.12 \mathrm{~m}, 0.35 \mathrm{~m}, 0.85 \mathrm{~m}, 1.35 \mathrm{~m}, 1.86 \mathrm{~m}$, $2.35 \mathrm{~m}$ and $2.6 \mathrm{~m}$ in 8 poles. Particle concentrations were measured in 5 poles namely TG1-TG5 at six heights of $0.12 \mathrm{~m}, 0.6 \mathrm{~m}, 1.1 \mathrm{~m}, 1.6 \mathrm{~m}, 2.1 \mathrm{~m}$ and $2.6 \mathrm{~m}$. All these measured results were served to verify the CFD performance. Fig. 3 illustrates the comparison of experimental data and numerical results. Fig. $3 a-b$ shows the normalized velocity $(u / U, U=0.14 \mathrm{~m} / \mathrm{s}$ is the supply air velocity) in the normalized height $(z / H, H=2.7 \mathrm{~m}$ is the height of the inpatient ward). Fig. 3c-d displays the normalized temperature $\left(\theta=\left(T-T_{i}\right) /\left(T_{e}-T_{i}\right), T_{i}\right.$ and $T_{e}$ are the temperature respectively at inlet and main exhaust) in the normalized height. The comparison results show that CFD have a good prediction of velocity and temperature at Pole 4 and Pole 5. In contrast to coarse grid arrangement, fine grid performs slightly better, especially for the velocity prediction above $z / H=0.8$.

The particle concentration also be measured to compared with the CFD result. Fig. $3 \mathrm{e}$ and $3 \mathrm{f}$ show the normalized particle concentration $\left(\sigma=\left(C_{p^{-}} C_{i}\right) /\left(C_{e^{-}} C_{i}\right), C_{p}, C_{i}\right.$ and $C_{e}$ are the particle concentration at the measuring location, ventilation supply inlet and ventilation exhausts respectively) in the normalized height. It depicts that, the fluctuation of the experiment and numerical value. Nevertheless, CFD simulation can basically describe the tendency 
along with the height. Therefore, the above results prove that present CFD simulations with the maximum grid size of $5 \mathrm{~cm}$ is effective and can be adopted in the following simulation.

\section{Results and discussion}

\subsection{Airflow field under different reference velocities $\left(U_{r e f}=0.2 \mathrm{~m} / \mathrm{s} \mathrm{or} 3 \mathrm{~m} / \mathrm{s}\right)$}

Figs. 4-5 show the distribution of normalized velocity magnitude $\left(U / U_{r e f}\right)$ and temperature at the center plane $y$ $=0$. In the case of $D=0.5 \mathrm{~m}$, the two manikins are close to each other and the susceptible person is located near the patient's wake. When $U_{r e f}=3 \mathrm{~m} / \mathrm{s}$, a clockwise vortex is formed between them (Fig. 4a1), and the thermal plume is destroyed by the high speed background wind (Fig. 4b1). In contrast when $U_{r e f}=0.2 \mathrm{~m} / \mathrm{s}$ (Fig. 4a2-b2), the buoyancy effect is evident. Due to the human thermal plume, there is a unified upward airflow which may lead the droplets to travel upwards (Fig. 4a2).

With the increase of $D$, the vortex disappears gradually (Fig. 5a1-d1), and airflow between two manikins approaches to the background when $U_{r e f}=3 \mathrm{~m} / \mathrm{s}$. When $D=1 \mathrm{~m}$, the susceptible person stays away from the patient's wake. For $D=1.5 \mathrm{~m}$ and greater, the downstream susceptible person is located far from the patient's wake region. In other words, there is no interaction between two manikins for larger social distance. In addition, the recirculation airflow at the leeward side of manikins could lead droplets to deposit on the back of human. When $U_{\text {ref }}=0.2 \mathrm{~m} / \mathrm{s}(\mathrm{Fig}$. 5a2-d2), the upward airflow is obvious as $D=0.5-5 \mathrm{~m}$ and overall wind pattern behaviors significantly differ from that of $U_{r e f}=3 \mathrm{~m} / \mathrm{s}$.

We further investigate the vertical velocity $\left(U_{z}\right)$ at center line $(x=0, y=0)$ to better show the upward convection (Fig. 6). A vortex can be found between two people when they are close, e.g. $D=0.5 \mathrm{~m}$ and $1 \mathrm{~m}$ when $U_{r e f}=3 \mathrm{~m} / \mathrm{s}$. However, only positive $U_{z}$ is observed for $U_{\text {ref }}=0.2 \mathrm{~m} / \mathrm{s}$. In particular, $U_{z}$ is within the range of $-0.11 \sim 0.04 \mathrm{~m} / \mathrm{s}$ in the 
manikin's breathing zone when $U_{\text {ref }}=3 \mathrm{~m} / \mathrm{s}$ and $D<1 \mathrm{~m}$, while $U_{z}$ can reach $0.12 \mathrm{~m} / \mathrm{s}$ when $U_{\text {ref }}=0.2 \mathrm{~m} / \mathrm{s}$ (Fig. 6b). This implies the exhaled droplets will be influenced much more in the breathing zone by the thermal plume when the background wind is weak and the social distance is less than $1 \mathrm{~m}$. The upward airflow is strong enough to carry the droplets upwards at first, then travel across the head of the susceptible person and finally move downwards and forwards. Fig. 6 also confirms that enlarging the social distance makes the upward airflow become smaller.

\subsection{Effect of background wind speed and relative humidity $(R H)$ on the dispersion of droplets with different}

\section{initial diameters $\left(d_{\mathrm{p}}=10 \mu \mathrm{m}, 50 \mu \mathrm{m}\right.$ and $\left.100 \mu \mathrm{m}\right)$}

Fig. 7 depicts the droplet distribution $\left(d_{\mathrm{p}}=10 \mu \mathrm{m}, 50 \mu \mathrm{m}\right.$ and $\left.100 \mu \mathrm{m}\right)$ at $t=10 \mathrm{~s}$ under $R H=35 \%$ for the cases of $U_{r e f}=3 \mathrm{~m} / \mathrm{s}$ and $0.2 \mathrm{~m} / \mathrm{s}$ when $D=1.5 \mathrm{~m}$. In wind-dominant cases (Fig. 7a1-3), droplets can horizontally travel further distance compared to that in buoyancy-dominant cases (Fig. 7b1-3). A great quantity of small droplets $(10 \mu \mathrm{m}, 50 \mu \mathrm{m})$ disperse along the stream-wise airflow and the vertical diffusion is much suppressed. When $U_{\text {ref }}=0.2 \mathrm{~m} / \mathrm{s}$, small droplets could easily diffuse upwards (Fig. 7b1-2) and their distribution in vertical direction is wider than that of when $U_{r e f}=3 \mathrm{~m} / \mathrm{s}$. In general, under either wind-dominate or buoyancy-dominate cases, $10 \mu \mathrm{m}$ and $50 \mu \mathrm{m}$ droplets have similar diffusion pattern, because only small droplet nuclei diffuse with the flow in a short time after evaporation. Larger difference can be found for $100 \mu \mathrm{m}$ droplets which tend to fall down quickly after being released due to the larger gravity force (Fig. 7a3,b3).

Additionally, $R H$ is proved to be the key factor for the droplet evaporation (Liu et al., 2017; Wei and Li, 2015). High $R H$ air can dramatically postpone the droplet evaporation due to its low potential in absorbing the water vapor (Ji et al., 2018), especially for $100 \mu \mathrm{m}$ droplets (Fig. 8). When $R H=35 \%$, droplets with the initial size of $100 \mu \mathrm{m}$ become $36.5 \mu \mathrm{m}$ droplet nuclei after the complete evaporation ( $t \sim 5 \mathrm{~s})$ under $R H=35 \%$, while they cannot evaporate 
completely under $R H=95 \%$ and their diameters retain around $90 \mu \mathrm{m}$. Therefore, a large number of droplets/droplet nuclei will accumulate in the region around susceptible person's head first and then fall down to deposit on the susceptible person's face, front and legs. When $R H=95 \%, 100 \mu \mathrm{m}$ droplets cannot evaporate completely and their final diameters retain around $90 \mu \mathrm{m}$. Droplets quickly fall down forced by the gravity and then deposit on the ground about 0.5-1m away from the patient (Xie et al., 2007).

\subsection{Exposure analysis of susceptible person under various social distances}

It is generally known that keeping distance between people can dramatically decrease the risk of infection (Feng et al., 2020; Liu et al., 2017; Wee et al., 2020; Xie et al., 2007). In this section, we calculate the inhalation fraction $(I F)$ and deposition fraction $(D F)$ for different $D(0.5 \mathrm{~m}, 1 \mathrm{~m}, 1.5 \mathrm{~m}, 3 \mathrm{~m}, 5 \mathrm{~m})$.

Fig. 9 shows $I F$ under different reference wind velocities. In general, $I F$ maintains a low level with the increasing $D$ (e.g. 1-700ppm when $U_{r e f}=3 \mathrm{~m} / \mathrm{s}$ ). The susceptible person inhales less droplets from the source patient with wider social distance (Fig. 9a). IF significantly decreases by up to ten times when $D$ increases from $0.5 \mathrm{~m}$ to $5 \mathrm{~m}$ (e.g. $700 \mathrm{ppm}$ when $D=0.5 \mathrm{~m}$ and $60 \mathrm{ppm}$ when $D=5 \mathrm{~m}$ under $R H=35 \%$ for $10 \mu \mathrm{m}$ droplets). $I F$ of smaller droplets is greater than that of larger droplets. The influence of droplet initial size is more significant than $R H$ at a certain distance ( $D=0.5 \mathrm{~m}$ and $1 \mathrm{~m})$. For example, the $I F$ difference between $R H=35 \%$ and $95 \%$ of $10 \mu \mathrm{m}$ droplets is $48 \mathrm{ppm}$, while it is $118 \mathrm{ppm}$ between $10 \mu \mathrm{m}$ and $50 \mu \mathrm{m}$ under $R H=35 \%$ when $D=0.5 \mathrm{~m}$. When $D>1.5 \mathrm{~m}$, the $I F$ difference caused by both two factors becomes smaller. It is also found that $I F$ decreases exponentially with $D$ (Fig. 9b). To quantify such process, the exponential decay rate $b$ of $I F\left(I F=I F_{0} * e^{-b(D-0.5)}\right)$ is calculated in Table 1. $b$ ranges from 0.93 to 1.06. The $I F$ of $50 \mu \mathrm{m}$ droplets seems to decrease more quickly with $D$ than that of $10 \mu \mathrm{m}$ droplets under $R H=35 \%$ (i.e. $b=0.95$ for $10 \mu \mathrm{m}$ droplets and 1.06 for $50 \mu \mathrm{m}$ droplets). Moreover, higher $R H$ can reduce the inhaled droplets by susceptible 
person and limit the distance for droplet dispersion (e.g. for $10 \mu \mathrm{m}$ droplets, $I F_{0}=709.94$ under $R H=35 \%$ and 646.72 under $R H=95 \%)$. Several droplets in the initial size of $100 \mu \mathrm{m}\left(\sim 10^{2}\right.$ smaller than $10 \mu \mathrm{m}$ and $\left.50 \mu \mathrm{m}\right)$ will be inhaled by susceptible people because most of them fall and deposit on the body surfaces.

When $U_{r e f}=0.2 \mathrm{~m} / \mathrm{s}$ (Fig. 9c), less droplets could be inhaled by the susceptible person, except for $100 \mu \mathrm{m}$ droplet dispersion under $R H=35 \%$ when $D=0.5 \mathrm{~m} .10 \mu \mathrm{m}$ and $50 \mu \mathrm{m}$ droplets tend to move upwards across susceptible person's head, especially when the buoyancy effect is significant in $D=0.5 \mathrm{~m}$ as shown in Fig. 4a2. $I F$ first increases when $D$ increases from $0.5 \mathrm{~m}$ to $1 \mathrm{~m}$, and then decreases with the increasing distance for $10 \mu \mathrm{m}$ and $50 \mu \mathrm{m}$ droplets. Such phenomenon may be due to the strong thermal body plumes when $D<1 \mathrm{~m}$. With the increasing $D$, the upward velocity between two people decreases (Fig. 6b). When $D$ increases from $1.5 \mathrm{~m}$ to $5 \mathrm{~m}, I F$ decreases in the similar trend except for $100 \mu \mathrm{m}$. For buoyancy dominant cases $\left(F_{r}<<1\right)$, with the increasing $D$ (e.g. $D=1.5 \mathrm{~m}$ to $\left.5 \mathrm{~m}\right)$, thermal body plume affects the limited region around human surface after droplets are released. The droplet initial size and $R H$ has less effect on $I F$ comparing to wind-driven cases.

The droplets deposited on the clothing or surfaces of the human body may also fall on the mucous membrane due to human behaviors, and subsequently cause infection. Fig. 10 reveals the droplet deposition on different parts of susceptible person. It is interesting to find that, when $U_{r e f}=3 \mathrm{~m} / \mathrm{s}, D F$ on face, front and legs are at least ten times greater than those when $U_{r e f}=0.2 \mathrm{~m} / \mathrm{s}$.

For large background wind cases $\left(U_{r e f}=3 \mathrm{~m} / \mathrm{s}\right.$, Fig. 10a1,b1,c1), $D F$ on face, front and legs decrease with $D$ (e.g. for $50 \mu \mathrm{m}$ droplets under $R H=95 \%, D F_{\text {face }}$ decreases from $18200 \mathrm{ppm}$ to1500ppm as $D$ increases from $0.5 \mathrm{~m}$ to $5 \mathrm{~m}$ ). Most droplets will deposit on the front of human body, and $D F_{\text {front }}$ is about 1.5 to 100 times more than $D F_{\text {face }}$. With the increase of droplet size, the deposition area gradually changes to the lower part of the susceptible person's body. 
For $U_{r e f}=0.2 \mathrm{~m} / \mathrm{s}$ (Fig. $\left.10 \mathrm{a} 2, \mathrm{~b} 2, \mathrm{c} 2\right)$, the trend of $D F$ is completely different from that of $U_{r e f}=3 \mathrm{~m} / \mathrm{s}$. It is mainly shown as a maximum $D F$ for $10 \mu \mathrm{m}$ and $50 \mu \mathrm{m}$ droplets when $D=1 \mathrm{~m}$. It is obvious to find the effect of $R H$ on large droplets $(100 \mu \mathrm{m})$, few of which will deposit on the susceptible person under $R H=95 \%$. While in dry environment $(R H=35 \%), 100 \mu \mathrm{m}$ droplets/droplet nuclei tend to deposit on the face of the susceptible person who is close to the patient $(D=0.5 \mathrm{~m})$, and the deposition area changes to the front and legs of human as $D$ increases.

\section{$5 \quad$ Limitations and future work}

Further research will take more processes and parameters into account. Firstly, future investigations will consider different respiratory activities (e.g. speaking, coughing, singing, sneezing), which may lead to complex jet speed and different initial characteristics of droplets (sizes, velocities, etc.). Secondly, this study considered the relatively ideal open space outdoors, while similar with reactive pollutant dispersion (e.g. Liu et al., 2020; Zhang et al., 2020a) and thermal environments by coupling turbulence and buoyancy forces with radiation processes (Antoniou et al., 2019; Chatterjee et al., 2019; Chen et al., 2020; Wang et al., 2020b) in street canyons, the droplet dispersion in real urban environment with street networks and buildings aligned at both sides is more complicated than an open space, which deserves in-depth research. Thirdly, relative humidity link to the ambient temperature is the key factor in the process of droplet evaporation and dispersion, which will be considered in future work. Finally, the composition and activity coefficient of the virus-laden droplets are of great importance for the transmission and infection risk depending on the specific characteristics of infectious diseases. 


\section{Conclusions}

In this study, we established a numerical model to study the integrated effect of background wind speed, relative humidity, thermal buoyancy and social distance on the evaporation and dispersion of exhaled droplets with different initial sizes in an open outdoor environment. The infection risks were evaluated by calculating the deposition fraction $(D F)$ and inhalation fraction $(I F)$ of droplets reaching the susceptible person.

Some meaningful findings are obtained:

(1) Thermal body plume is completely destroyed when the background wind speed is relatively large (e.g. $U_{\text {ref }}=3 \mathrm{~m} / \mathrm{s}$, $\left.F_{r} \sim 10\right)$, while it dominates the droplet transmission under weak background wind $\left(U_{r e f}=0.2 \mathrm{~m} / \mathrm{s}, F_{r} \sim 0.01\right)$.

(2) Inhalation fraction decay exponentially and the decay rate $(b)$ is from 0.93 to $1.06\left(I F=I F_{0} e^{-b(D-0.5)}\right)$ determined by the droplet initial diameters and relative humidity under $U_{r e f}=3 \mathrm{~m} / \mathrm{s}$.

(3) The deposition fraction under $U_{r e f}=0.2 \mathrm{~m} / \mathrm{s}$ is at least 10 times smaller than that under $U_{\text {ref }}=3 \mathrm{~m} / \mathrm{s}$, as we only consider the worst exposure case in outdoor open space that the susceptible person locates face-to-face downwind region of the source infected person.

(4) Wind effect on the droplet transport and deposition in outdoors is complicated because of the wake flow patterns and localized secondary flow intensities between two people. For wind dominant cases, the closer the two people are, the higher the risk infection is. The exposure risk is highest if $D=1 \mathrm{~m}$ in weak background wind environment.

(5) Followed by droplet initial size, relative humidity is another key factor. For relatively large droplet under wet environment, the exposure risk decreases more quickly than small droplet in dry environment with $D$.

Therefore, we conclude that it is necessary to keep distance between people in outdoors to reduce the infection risk. Avoid standing in the area directly downstream of the prevailing wind direction and try not to talk to people 
face to face. Under the weak background wind environment, keep at least $1.5 \mathrm{~m}$ to protect yourself. Although further investigations are still required before providing practical guidelines, this work attempts to assess the impacts of relative humidity on droplet transmissions with different social distances between two people in outdoor environment.

\section{Acknowledgements}

Zhiwen Luo and Jian Hang would like to thank the financial support from UK GCRF Rapid Response Grant on 'Transmission of SARS-CoV-2 virus in crowded indoor environment'. This study was also financially supported by the National Natural Science Foundation of China (grant number. 51811530017, 42005069 and $\underline{41875015}$ ) and STINT (Sweden, grant number dnr CH2017-7271), the Key projects of Guangdong Natural Science Foundation (China, grant number 2018B030311068) as well as Special Fund (International Cooperation) Project for Science and Technology Innovation Strategy of Guangdong Province (China, grant number 2019A050510021), and the Opening Fund of State Key Laboratory of Green Building in Western China (No. LSKF202106), and Guangdong Province Key Laboratory for Climate Change and Natural Disaster Studies (Grant 2020B1212060025).

\section{References}

ANSYS Inc, ANSYS FLUENT User's Guide, (version 15.0).

Antoniou, N., Montazeri, H., Neophytou, M., Blocken, B., 2019. CFD simulation of urban microclimate: Validation using high-resolution field measurements. Science of the Total Environment. 695, 133743.

Asadi, S., Bouvier, N., Wexler, A., Ristenpart, W. 2020. The coronavirus pandemic and aerosols: Does COVID-19 transmit via expiratory particles? Aerosol Science and Technology, 54(6), 635-638.

Bartzis, J., Efthimiou, G., Andronopoulos, S. 2015. Modelling short term individual exposure from airborne hazardous 
releases in urban environments. Journal of Hazardous Materials. 300, 182-188.

Bourouiba, L. 2020. Turbulent gas clouds and respiratory pathogen emissions: potential implications for reducing transmission of COVID-19. Journal of the American Medical Association. 323(18), 1837-1838.

Brown, M., Lawson, R., DeCroix, D., Lee, R. 2001. Comparison of centerline velocity measurements obtained around 2D and 3D building arrays in a wind tunnel. Report LA-UR-01-4138, Los Alamos National Laboratory. Los Alamos, pp.7.

Centers for Disease control and Prevention. Social distancing. https://www.cdc.gov/coronavirus/2019-ncov/globalcovid-19/index.html. Accessed 15 November 2020

Chatterjee, S., Khan, A., Dinda, A., Mithun, S., Khatun, R., Akbari, H., Kusaka, H., Mitra, C., Bhatti, S.S., Doan, Q. Van, Wang, Y., 2019. Simulating micro-scale thermal interactions in different building environments for mitigating urban heat islands. Science of the Total Environment. 663, 610-631.

Chen, G., Wang, D., Wang, Q., Li, Y., Wang, X., Hang, J., Gao, P., Ou, C., Wang, K., 2020. Scaled outdoor experimental studies of urban thermal environment in street canyon models with various aspect ratios and thermal storage. Science of the Total Environment. 726, 138147.

Chen, L., Hang, J., Sandberg, M., Claesson, L., Di Sabatino, S., Wigo, H. 2017. The impacts of building height variations and building packing densities on flow adjustment and city breathability in idealized urban models. Building and Environment. 118, 344-361.

Chen, Q. 1995. Comparison of different $k-\varepsilon$ models for indoor airflow computations. Numerical Heat Transfer, Part B: Fundamentals 28, 353-369.

Dombrovsky, L., Fedorets, A., Levashov, V., Kryukov, A., Bormashenko, E., Nosonovsky, M. 2020. Modeling evaporation of water droplets as applied to survival of airborne viruses. Atmosphere. 11(9), 1-17.

Doremalen, N., Morris, D., Holbrook, M., Gamble, A., Williamson, B., Tamin, A., Harcourt, J., Thornburg, N., Gerber, 
S., Lioyd-Smith, J., Wit, E., Munster, V. 2020. Aerosol and surface stability of SARS-CoV-2 as compared with SARSCoV-1. The New England and Journal of Medicine. 382(9).

Feng, Y., Marchal, T., Sperry, T., Yi, H. 2020. Influence of wind and relative humidity on the social distancing effectiveness to prevent COVID-19 airborne transmission: A numerical study. Journal of Aerosol Science. 147, 105585.

Franke, J., Hellsten, A., Schlünzen, K. H., Carissimo, B. 2011. The COST 732 Best Practice Guideline for CFD simulation of flows in the urban environment: A summary. International Journal of Environment and Pollution. 44(1-4), 419-427.

Gao, C., Li, Y., Wei, J., Cotton, S., Hamilton, M., Wang, L., Cowling, B. 2021. Multi-route respiratory infection: When a transmission route may dominate. Science of the Total Environment. 752. 141856.

Gupta, J., Lin, C., Chen, Q. 2012. Risk assessment of airborne infectious diseases in aircraft cabins. Indoor Air. 22(5), 388-395.

Habilomatis, G., Chaloulakou, A. 2015. A CFD modelling study in an urban street canyon for ultrafine particles and population exposure: the intake fraction approach. Science of the Total Environment. 530-531, 227-232.

Hang, J., Li, Y., Ching, W., Wei, J., Jin, R., Liu, L., Xie, X. 2015. Potential airborne transmission between two isolation cubicles through a shared anteroom. Building and Environment. 89, 264-278.

Hang, J., Li, Y., Jin, R. 2014. The influence of human walking on the flow and airborne transmission in a six-bed isolation room: tracer gas simulation. Building and Environment. 77, 119-134.

Hasan, S., Sobolev, K., Nosonovsky, M. 2021. Evaporation of droplets capable of bearing viruses airborne and on hydrophobic surfaces. Journal of Applied Physics. January. 
He, L., Hang, J., Wang X., Lin B., Li, X., Lan, G. 2017. Numerical investigations of flow and passive pollutant exposure in high-rise deep street canyons with various street aspect ratios and viaduct settings. Science of the Total Environment. 584-585, 189-206.

Irwin, J. 1979. A theoretical variation of the wind profile power-law exponent as a function of surface roughness and stability. Atmospheric Environment.13(1),191-194.

Ji, Y., Qian, H., Ye, J., Zheng, X. 2018. The impact of ambient humidity on the evaporation and dispersion of exhaled breathing droplets: A numerical investigation. Journal of Aerosol Science. 115, 164-172.

Kissler, S., Tedijanto, C., Goldstein, E., Grad, Y., Lipsitch, M. 2020. Projecting the transmission dynamics of SARSCoV-2 through the post pandemic period. Science. 368(6493), 860-868.

Kutter, J., Spronken, M., Fraaij, P., Fouchier, R., Herfst, S. 2018. Transmission routes of respiratory viruses among humans. Current Opinion in Virology. 28, 142-151.

Li, Y., Ching, W., Qian, H., Yuen, P., Seto, W., Kwan, J., Leung, M., Yu, S. 2007. An evaluation of the ventilation performance of new SARS isolation wards in nine hospitals in Hong Kong. Indoor and Built Environment. 16(5), 400-410.

Li, Y., Qian, H., Hang, J., Chen, X., Hong, L., Liang, P., Li, J., Xiao, S., Wei, J., Liu, L., Kang, M. 2020. Evidence for probable aerosol transmission of SARS-CoV-2 in a poorly ventilated restaurant. 1-19.

Lien, F., Yee, E. 2004. Numerical modeling of the turbulent flow developing within and over a 3-D building array, part I: A high-resolution Reynolds-averaged Navier-Stokes approach. Boundary-layer Meteorology. 112, 427-466.

Lin, M., Hang, J., Li, Y., Luo, Z., Sandberg, M. 2014. Quantitative ventilation assessments of idealized urban canopy layers with various urban layouts and the same building packing density. Building and Environment. 79, 152-167.

Lindsley, W., Blachere, F., Thewlis, R., Kristina, A., Cao, G., Palmer, J., Clark, K., Fisher,M., Khakoo, R., Beezhold, D. 2010. Measurements of airborne influenza virus in aerosol particles from human coughs. PLoS ONE. 5(11), 15100. 
Liu, C., Ng, C., Wong, C. 2015. A theory of ventilation estimate over hypothetical urban areas. Journal of Hazardous Materials. 296, 9-16.

Liu, F., Qian, H., Luo, Z., Wang, S., Zheng, X. 2020. A laboratory study of the expiratory airflow and particle dispersion in the stratified indoor environment. Building and Environment. 180.

Liu, J., Cui, S., Chen, G., Zhang, Y., Wang, X., Wang, Q., Gao, P., Hang, J. 2020. The influence of solar natural heating and NO-O3 photochemistry on flow and reactive pollutant exposure in 2D street canyons. Science of the Total Environment, 759.143527.

Liu, L., Li, Y, Nielsen, P., Wei, J., Jensen, R. 2017. Short-range airborne transmission of expiratory droplets between two people. Indoor Air. 27(2), 452-462.

Liu, P., Wang, B., Zhao, X., Duan, X., Huang, N., Chen, Y., Wang, L. 2010. Research on inhalation rate of Chinese adults. Journal of Environment and Health (in Chinese). 31(11), 953-956.

Liu, X., Niu, J., Kwok, K. 2011a. Analysis of concentration fluctuations in gas dispersion around high-rise building for different incident wind directions. Journal of Hazardous Materials. 192, 1623-1632.

Liu, X., Niu, J., Kwok, K., Wang, J., Li, B. 2011b. Local characteristics of cross-unit contamination around high-rise building due to wind effect: mean concentration and infection risk assessment. Journal of Hazardous Materials. 192, $160-167$.

Marr, L., Tang, J., Van Mullekom, J., Lakdawala, S. 2019. Mechanistic insights into the effect of humidity on airborne influenza virus survival, transmission and incidence. Journal of the Royal Society Interface. 16(150).

Mui, K., Wong, L., Wu, C., Lai, A. 2009. Numerical modeling of exhaled droplet nuclei dispersion and mixing in indoor environments. Journal of Hazardous Materials. 167 (1-3), 736-744.

Nazarian, N., Kleissl, J. 2016. Realistic solar heating in urban areas: Air exchange and street-canyon ventilation. Building and Environment. 95, 75-93. 
Potter, J., Matthews, L., Lemm, J., Spector, S. 1963. Human pulmonary secretions in health and disease. Annals of the New York Academy of Sciences. 106, 692-697.

Qian, H., Li, Y. 2010. Removal of exhaled particles by ventilation and deposition in a multibed airborne infection isolation room. Indoor Air. 20(4), 284-297.

Scungio, M., Stabile, L., Rizza, V., Pacitto, A., Russi, A., Buonanno, G. 2018. Lung cancer risk assessment due to traffic-generated particles exposure in urban street canyons: A numerical modelling approach. Science of the Total Environment. 631-632, 1109-1116.

Shen, Y., Li, C., Dong, H., Wang, Z., Martinez, L., Sun, Z., Handel, A., Chen, Z., Chen, E., Ebell, M., Wang, F., Yi, B., Wang, H., Wang, X., Wang, A., Chen, B., Qi, Y., Liang, L., Li, Y., Ling, F., Chen, J., Xu, G. 2020. Community outbreak investigation of SARS-CoV-2 transmission among bus riders in eastern china. JAMA Internal Medicine. 17.

Tominaga, Y., Mochida, A., Yoshie, R., Kataoka, H., Nozu, T., Yoshikawa, M., Shirasawa, T. 2008. AIJ guidelines for practical applications of CFD to pedestrian wind environment around buildings. Journal of Wind Engineering and Industrial Aerodynamics. 96(10-11), 1749-1761.

Tung, N., Cheng, P., Chi, K., Hsiao, T., Jones, T., BéruBé, K., Ho, K. F., Chuang, H. 2021. Particulate matter and SARS-CoV-2: A possible model of COVID-19 transmission. Science of the Total Environment. 750, 141532.

Tung, Y., Shih, Y., Hu, S. 2009. Numerical study on the dispersion of airborne contaminants from an isolation room in the case of door opening. Applied Thermal Engineering. 29(8-9), 1544-1551.

Wang, J., Yang, W., Pan, L., Ji, J., Shen, J., Zhao, K., Ying, B., Wang, X., Zhang, L., Wang, L., Shi, X. 2020a. Prevention and control of COVID-19 in nursing homes, orphanages, and prisons. Environmental Pollution. 266, 115161.

Wang, W., Yao, X., Shu, J., 2020b. Air advection induced differences between canopy and surface heat islands. Science of the Total Environment.725, 138120. 
Wee, L., Conceicao, E., Sim, X., Aung, M., Tan, K., Wong, H., Wijaya, L., Tan, B., Ling, M., Venkatachalam, I. 2020. Minimizing intra-hospital transmission of COVID-19: the role of social distancing. Journal of Hospital Infection. 105(2), 113-115.

Wei, J., Li, Y. 2015. Enhanced spread of expiratory droplets by turbulence in a cough jet. Building and Environment. 93, 86-96.

World Health Organization. Coronavirus disease (COVID-19) advice for the public. https://www.who.int/emergencies/diseases/novel-coronavirus-2019/advice-for-public. Accessed 15 November $2020 b$.

World Health Organization. Coronavirus disease (COVID-19) pandemic. Numbers at a glance.

https://www.who.int/emergencies/diseases/novel-coronavirus-2019. Accessed 15 November 2020a.

Xie, X., Li, Y., Chwang, A., Ho, P., Seto, W. 2007. How far droplets can move in indoor environments-revisiting the Wells evaporation-falling curve. Indoor air. 17(3), 211-225.

Xie, X., Li, Y., Sun, H., Liu, L. 2009. Exhaled droplets due to talking and coughing. Journal of the Royal Society Interface. 6, 703-714.

Yang, H., Chen, T., Lin, Y., Buccolieri, R., Mattsson, M., Zhang, M., Hang, J., Wang, Q. 2020a. Integrated impacts of tree planting and street aspect ratios on $\mathrm{CO}$ dispersion and personal exposure in full-scale street canyons. Building and Environment. 169: 106529.

Yang, X., Ou, C., Yang, H., Liu, L., Song, T., Kang, M., Lin, H., Hang, J. 2020b. Transmission of pathogen-laden expiratory droplets in a coach bus. Journal of Hazardous Materials. 397, 122609. 
Yang, X., Zhang, Y., Hang, J., Lin, Y., Mattsson, M., Sandberg, M., Zhang, M., Wang, K. 2020c. Integrated assessment of indoor and outdoor ventilation in street canyons with naturally-ventilated buildings by various ventilation indexes. Building and Environment. 169, 106528.

Yao, Y., Pan, J., Wang, W., Liu, Z., Kan, H., Qiu, Y., Meng, X., Wang, W. 2020. Association of particulate matter pollution and case fatality rate of COVID-19 in 49 Chinese cities. Science of the Total Environment. 741, 140396.

Yin, Y., Xu, W., Gupta, J., Guity, A., Marmion, P., Manning, A., Gulick, B., Zhang, X., Chen, Q. 2009. Experimental study on displacement and mixing ventilation systems for a patient ward. HVAC and R Research. 15(6), 1175-1191.

Yu, I., Li, Y., Wong, T, Tam, W., Chan, A., Lee, J, Leung, D., Ho, T. 2004. Evidence of Airborne Transmission of the Severe Acute Respiratory Syndrome Virus. New England Journal of Medicine. 350(17), 1731-1739.

Zhang, K., Chen, G., Wang, X., Liu, S., Mak, C., Fan, Y., Hang, J. 2019. Numerical evaluations of urban design technique to reduce vehicular personal intake fraction in deep street canyons. Science of the Total Environment. 653, 968-994.

Zhang, K., Chen, G., Zhang, Y., Liu, S., Wang, X., Wang, B., Hang, J. 2020a. Integrated impacts of turbulent mixing and $\mathrm{NO}_{x}-\mathrm{O}_{3}$ photochemistry on reactive pollutant dispersion and intake fraction in shallow and deep street canyons. Science of the Total Environment. 712, 135553.

Zhang, L., Li, Y. 2012. Dispersion of coughed droplets in a fully-occupied high-speed rail cabin. Building and Environment. 47, 58-66.

Zhang, X., Ji, Y., Yue, Y., Liu, H., Wang, J. 2020b. Infection risk assessment of COVID-19 through aerosol transmission: a case study of south China seafood market. Environmental Science and Technology.

Zhang, X., Weerasuriya, A., Tse, K. 2020c. CFD simulation of natural ventilation of a generic building in various incident wind directions: Comparison of turbulence modelling, evaluation methods, and ventilation 
mechanisms. Energy and Buildings. 229, 110516.

Zhao, B., Zhang, Z., Li, X. 2005. Numerical study of the transport of droplets or particles generated by respiratory system indoors. Building and Environment. 40(8), 1032-1039.

Zhao, Y., Aarnink, A., Dijkman, R., Fabri, T., de Jong, M., Groot Koerkamp, P. 2012. Effects of temperature, relative humidity, absolute humidity, and evaporation potential on survival of airborne Gumboro vaccine virus. Applied and Environmental Microbiology. 78(4), 1048-1054.

\section{Figure list}

Fig. 1. (a) Sketch and size of the domain (take case with $D=0.5 \mathrm{~m}$ as example), (b) The overall grid arrangement, (c) Body parts of susceptible person, (d) Flowchart of this study.

Fig. 2. Overview of one-bed isolation room in CFD simulation according to Yin et al. (2009)

Fig. 3. Vertical profiles of (a-b) normalized velocity $(u / U)$, (c-d) temperature $\left(\theta=\left(T-T_{i}\right) /\left(T_{e}-T_{i}\right)\right)$ and (e-f) particle concentration $\left(\sigma=\left(C_{p^{-}} C_{i}\right) /\left(C_{e}-C_{i}\right)\right)$ at Pole4, Pole5 and TG4, TG5.

Fig. 4. Normalized velocity magnitude $\left(U / U_{\text {ref }}\right)$ and temperature around humans at the center plane $(y=0)$ for case with $D=0.5 \mathrm{~m}:(\mathrm{a} 1-\mathrm{b} 1) U_{r e f}=3 \mathrm{~m} / \mathrm{s},(\mathrm{a} 2-\mathrm{b} 2) U_{r e f}=0.2 \mathrm{~m} / \mathrm{s}$

Fig. 5. Normalized velocity magnitude $\left(U / U_{r e f}\right)$ around humans at the center plane $(y=0)$ for case with $D=1 \mathrm{~m}, 1.5 \mathrm{~m}$, $3 \mathrm{~m}, 5 \mathrm{~m}:(\mathrm{a} 1-\mathrm{d} 1) U_{r e f}=3 \mathrm{~m} / \mathrm{s}$, (a2-d2) $U_{r e f}=0.2 \mathrm{~m} / \mathrm{s}$.

Fig. 6. Vertical velocity $\left(U_{z}\right)$ at the center line $(x=0, y=0)$ under (a) $U_{r e f}=3 \mathrm{~m} / \mathrm{s}$, (b) $U_{\text {ref }}=0.2 \mathrm{~m} / \mathrm{s}$

Fig. 7. Droplets dispersion $(10 \mu \mathrm{m}, 50 \mu \mathrm{m}$ and $100 \mu \mathrm{m})$ under $(\mathrm{a} 1-\mathrm{a} 3) U_{r e f}=3 \mathrm{~m} / \mathrm{s}$ and $(\mathrm{b} 1-\mathrm{b} 3) U_{r e f}=0.2 \mathrm{~m} / \mathrm{s}$ at $t=10 \mathrm{~s}$ when $D=1.5 \mathrm{~m}$ and $R H=35 \%$.

Fig. 8. Droplets dispersion of $100 \mu \mathrm{m}$ under (a) $R H=35 \%$ and (b) $R H=95 \%$ when $D=1.5 \mathrm{~m}$ and $U_{\text {ref }}=0.2 \mathrm{~m} / \mathrm{s}$.

Fig. 9. Normalized droplet number inhaled by the susceptible person $(I F)$ under (a,b) $U_{r e f}=3 \mathrm{~m} / \mathrm{s}$ and (c) $U_{r e f}=0.2 \mathrm{~m} / \mathrm{s}$.

Fig. 10. Normalized droplet number of deposited on different part of the susceptible person under $U_{\text {ref }}=3 \mathrm{~m} / \mathrm{s}$ and $U_{\text {ref }}=0.2 \mathrm{~m} / \mathrm{s}$ : deposition fraction on (a1-2) face $\left(D F_{\text {face }}\right)$; (b1-2) front $\left(D F_{\text {front }}\right)$; (c1-2) legs $\left(D F_{\text {legs }}\right)$. 
Table.1 Exponential decay fitting of $I F$ toward social distance $\left(I F=I F_{0} * e^{-b(D-0.5)}\right)$

\begin{tabular}{cc|cc}
\hline \multicolumn{2}{c|}{ Cases } & $I F_{0}(\mathrm{ppm})$ & Decay rate $b$ \\
\hline \multirow{3}{*}{$R H=35 \%$} & $10 \mu \mathrm{m}$ & 709.94 & 0.95 \\
& $50 \mu \mathrm{m}$ & 563.73 & 1.06 \\
& $100 \mu \mathrm{m}$ & 9.86 & 1.06 \\
\hline \multirow{2}{*}{$R H=95 \%$} & $10 \mu \mathrm{m}$ & 646.72 & 1.02 \\
& $50 \mu \mathrm{m}$ & 299.43 & 0.93 \\
\hline
\end{tabular}



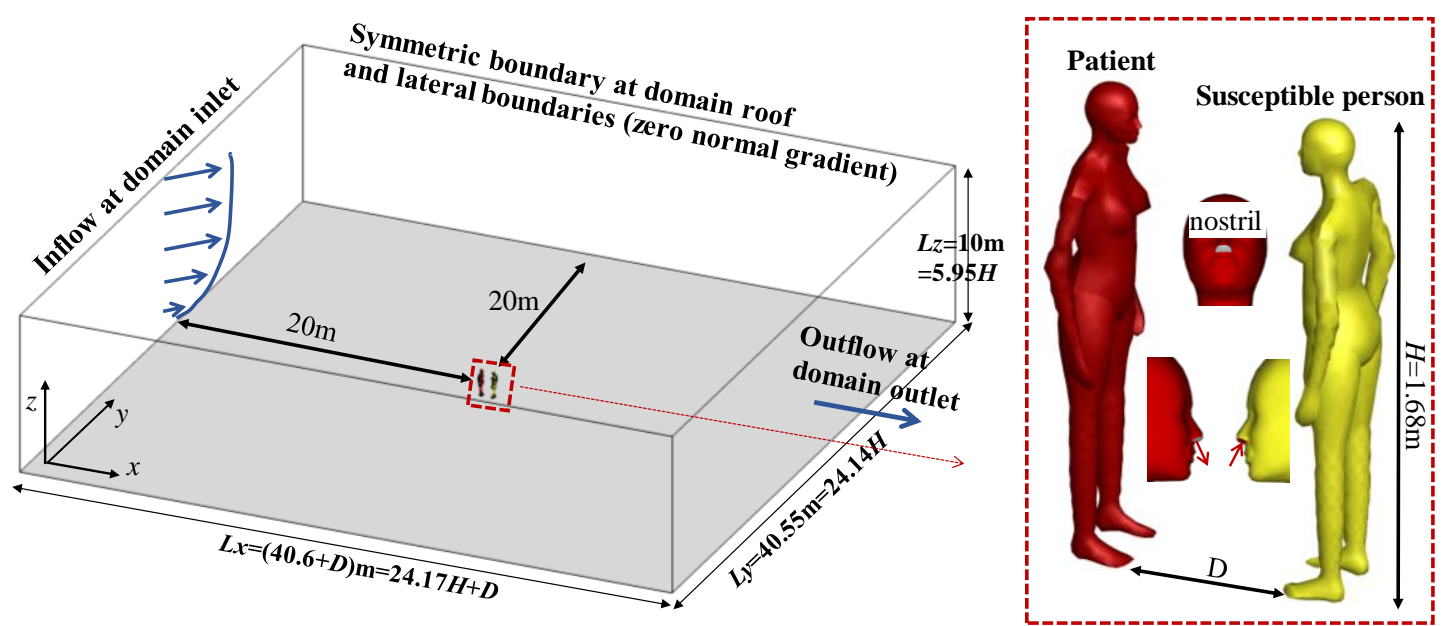

(a)
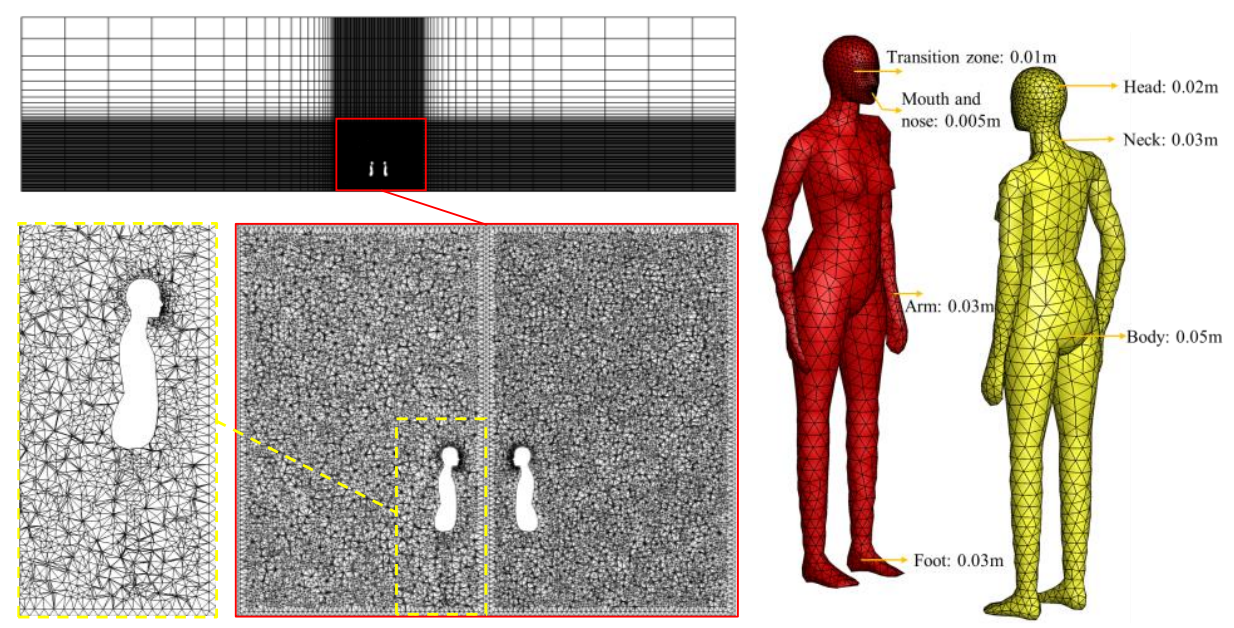

(b)

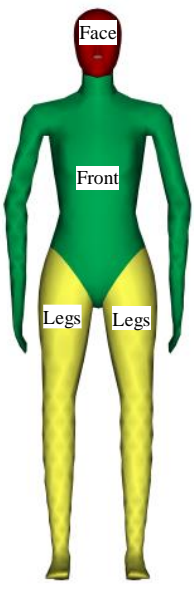

(c)

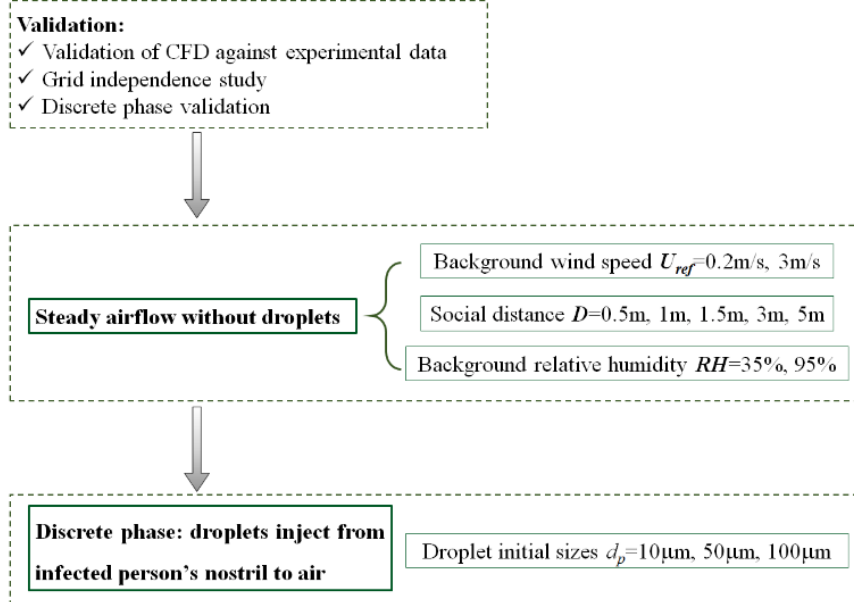

Discussion:

$\checkmark$ Airflow under different background conditions

$\checkmark$ Droplet dispersion

$\checkmark$ Exposure analysis:

Deposition fraction $D F=N_{\text {deposited }} / N_{\text {total }}$ Inhalation fraction $I F=N_{\text {inhaled }} / N_{\text {total }}$

(d)

Fig. 1. (a) Sketch and size of the domain (take case with $D=0.5 \mathrm{~m}$ as example), (b) The overall grid arrangement, (c) Body parts of susceptible person, (d) Flowchart of this study. 


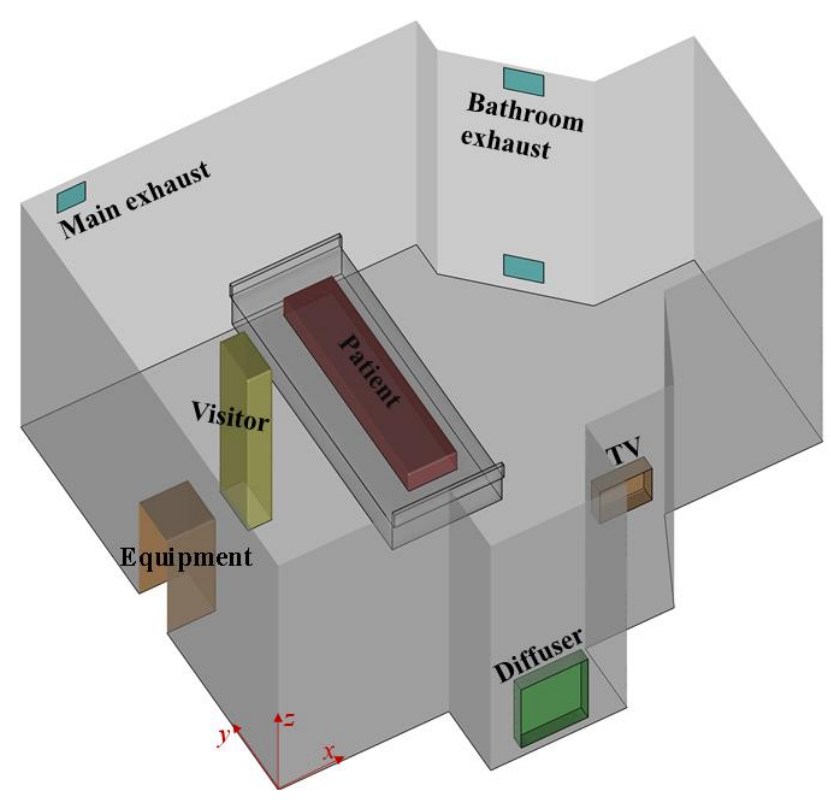

(a)

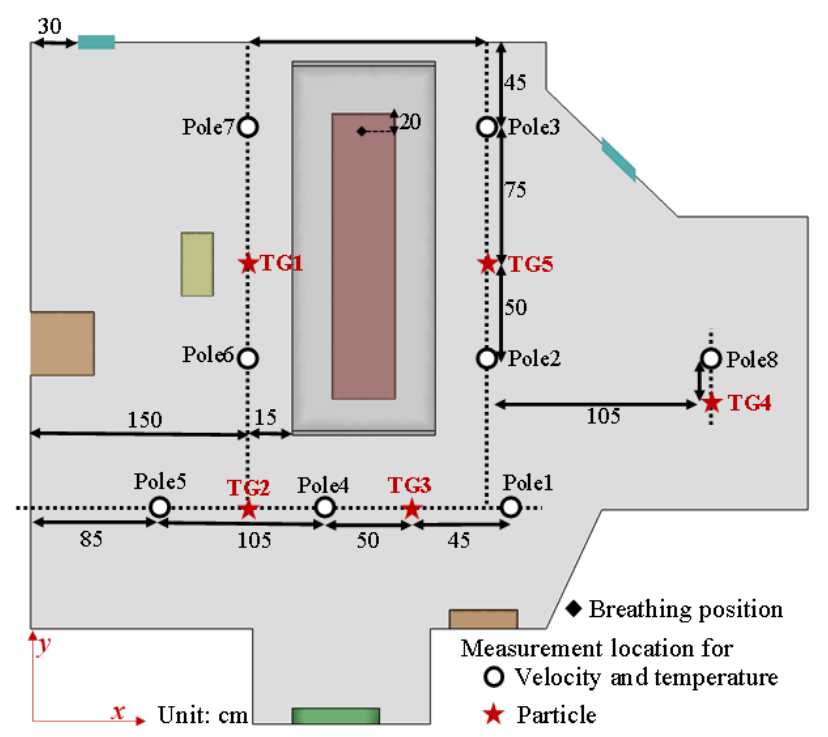

(b)

Fig. 2. Overview of one-bed isolation room in CFD simulation according to Yin et al. (2009) 


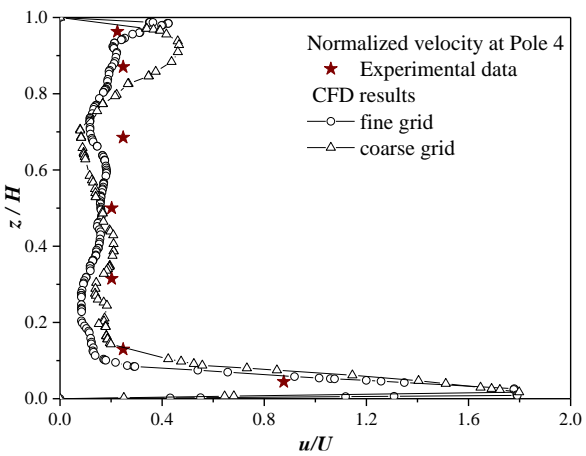

(a)

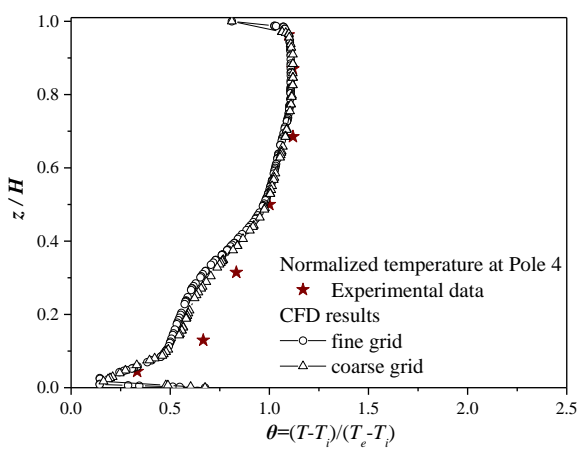

(c)

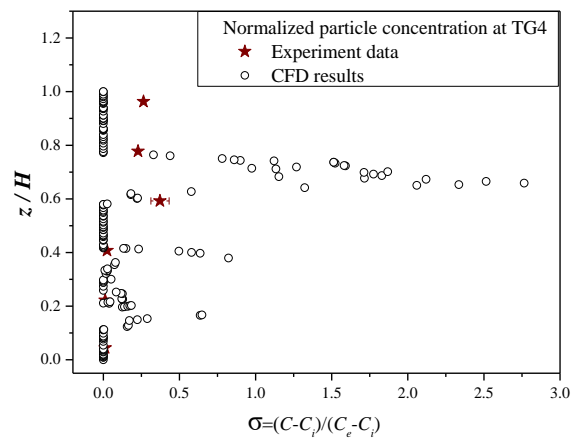

(e)

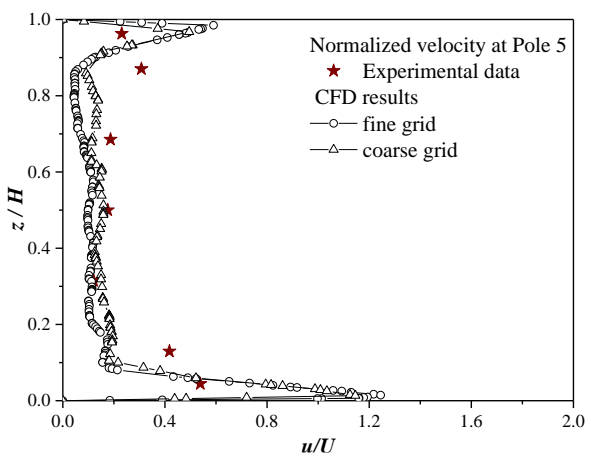

(b)

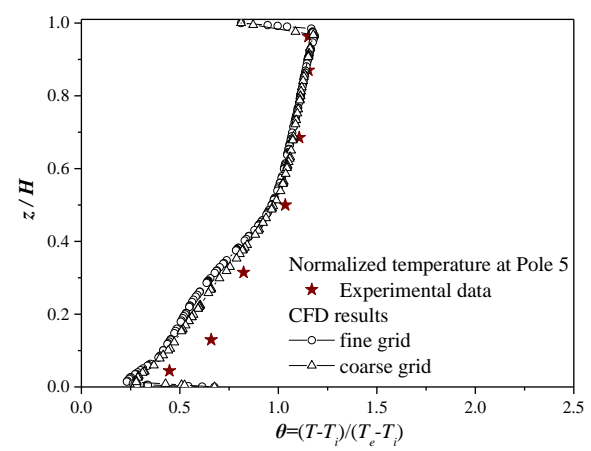

(d)

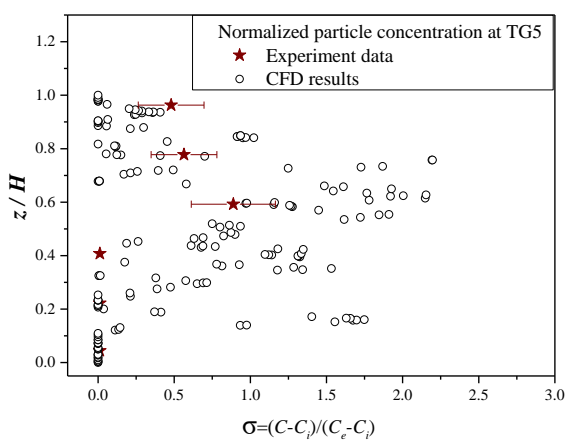

(f)

Fig. 3. Vertical profiles of (a-b) normalized velocity $(u / U)$, (c-d) temperature $\left(\Theta=\left(T-T_{i}\right) /\left(T_{e}-T_{i}\right)\right)$ and (e-f) particle concentration $\left(\sigma=\left(C_{p^{-}}-C_{i}\right) /\left(C_{e^{-}} C_{i}\right)\right)$ at Pole4, Pole5 and TG4, TG5. 
Flow field for $D=0.5 \mathrm{~m}, U_{r e f}=3 \mathrm{~m} / \mathrm{s}$

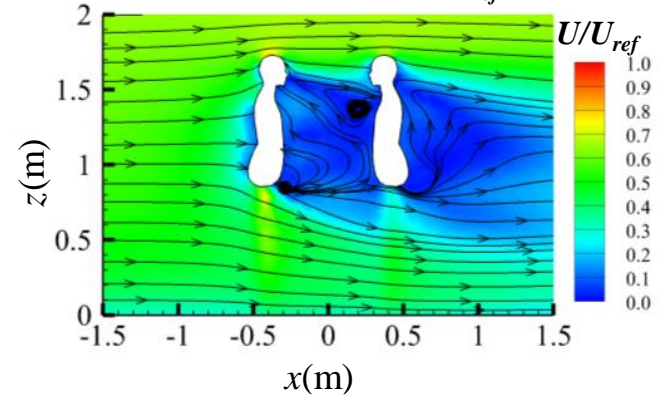

(a1)

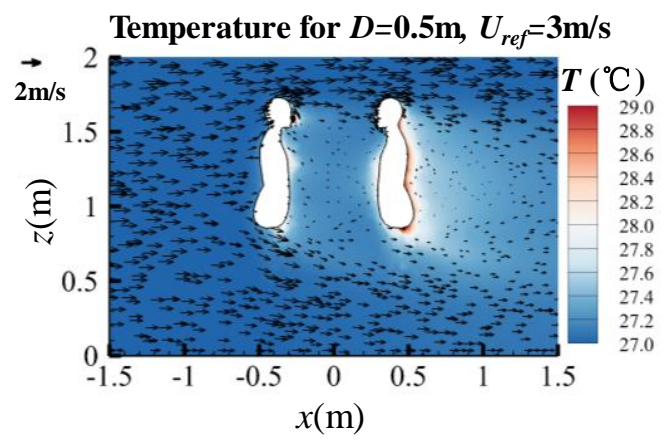

(b1)
Flow field for $D=0.5 \mathrm{~m}, U_{r e f}=0.2 \mathrm{~m} / \mathrm{s}$

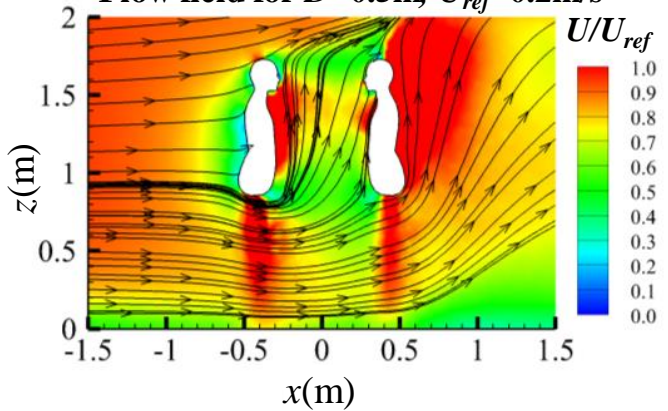

(a2)

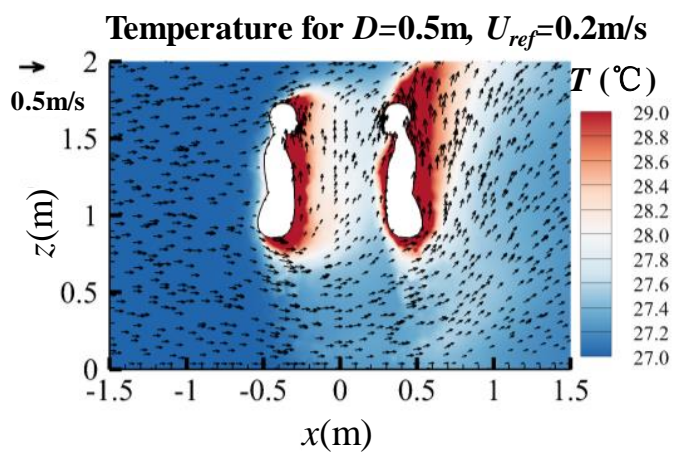

(b2)

Fig. 4. Normalized velocity magnitude $\left(U / U_{\text {ref }}\right)$ and temperature around humans at the center plane $(y=0)$ for case with $D=0.5 \mathrm{~m}$ : (a1-b1) $U_{r e f}=3 \mathrm{~m} / \mathrm{s},(\mathrm{a} 2-\mathrm{b} 2) U_{r e f}=0.2 \mathrm{~m} / \mathrm{s}$. 
$U / U_{\text {ref }} \begin{array}{llllllllllllll}0.0 & 0.1 & 0.2 & 0.3 & 0.4 & 0.5 & 0.6 & 0.7 & 0.8 & 0.9 & 1.0\end{array}$

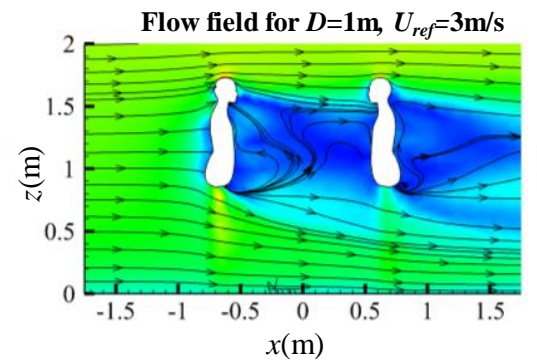

(a1)

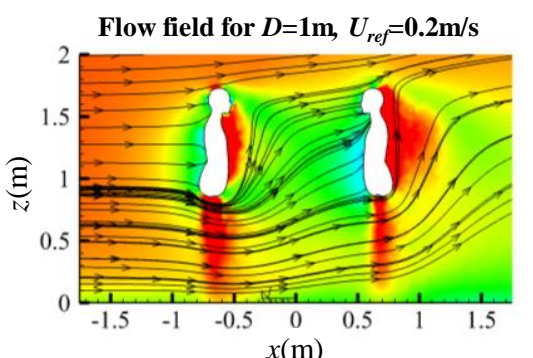

(a2)

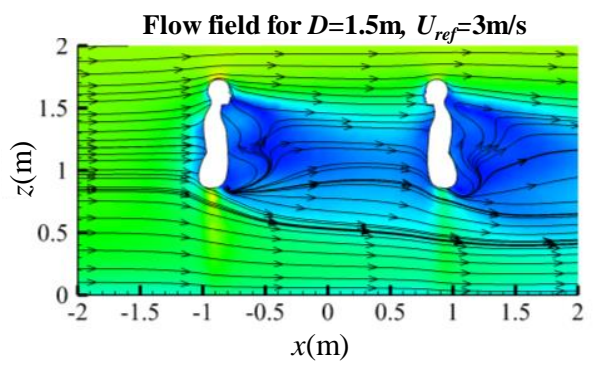

(b1)

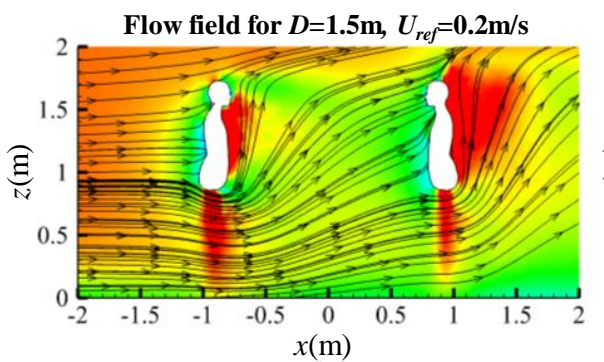

(b2)

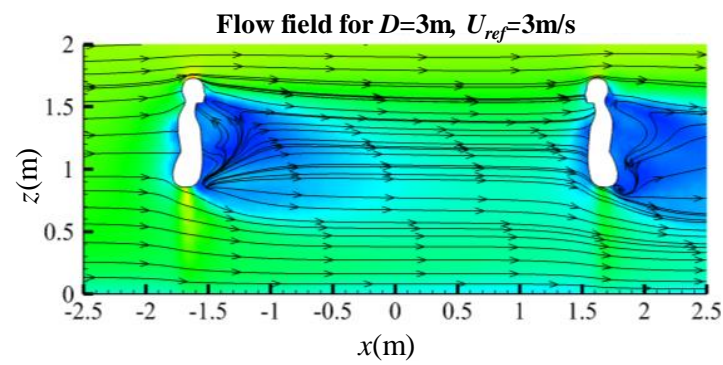

(c1)

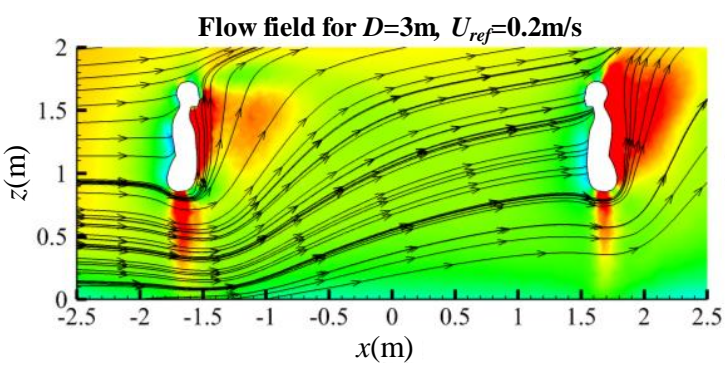

(c2)

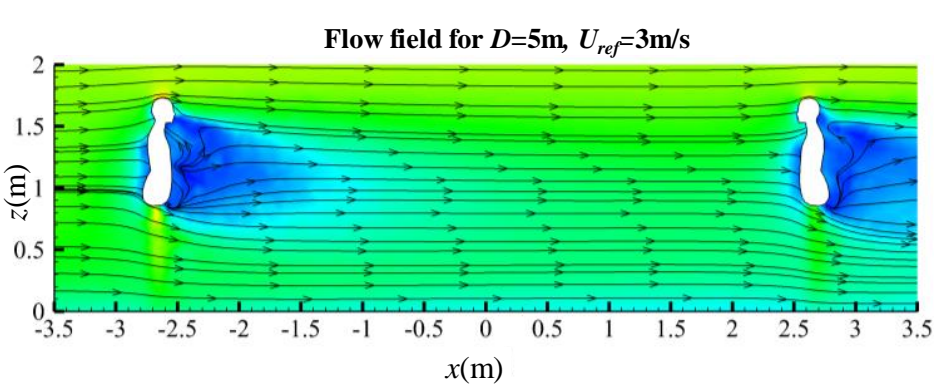

(d1)

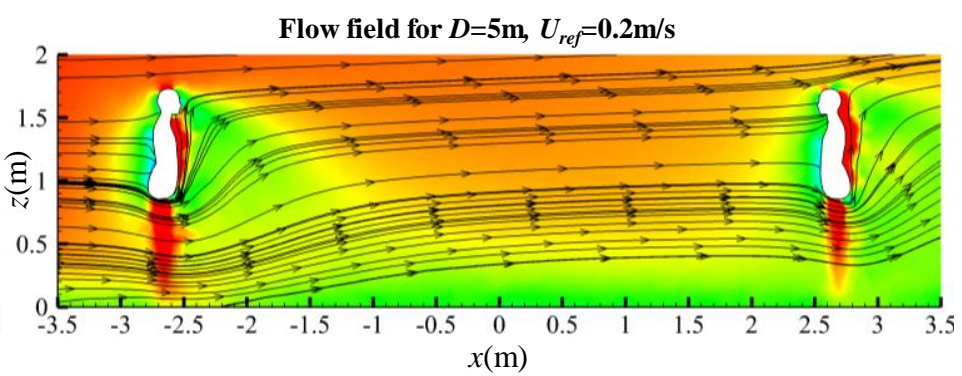

(d2)

Fig. 5. Normalized velocity magnitude $\left(U / U_{r e f}\right)$ around humans at the center plane $(y=0)$ for case with $D=1 \mathrm{~m}, 1.5 \mathrm{~m}, 3 \mathrm{~m}, 5 \mathrm{~m}:(\mathrm{a} 1-\mathrm{d} 1) U_{r e f}=3 \mathrm{~m} / \mathrm{s},(\mathrm{a} 2-\mathrm{d} 2) U_{r e f}=0.2 \mathrm{~m} / \mathrm{s}$. 


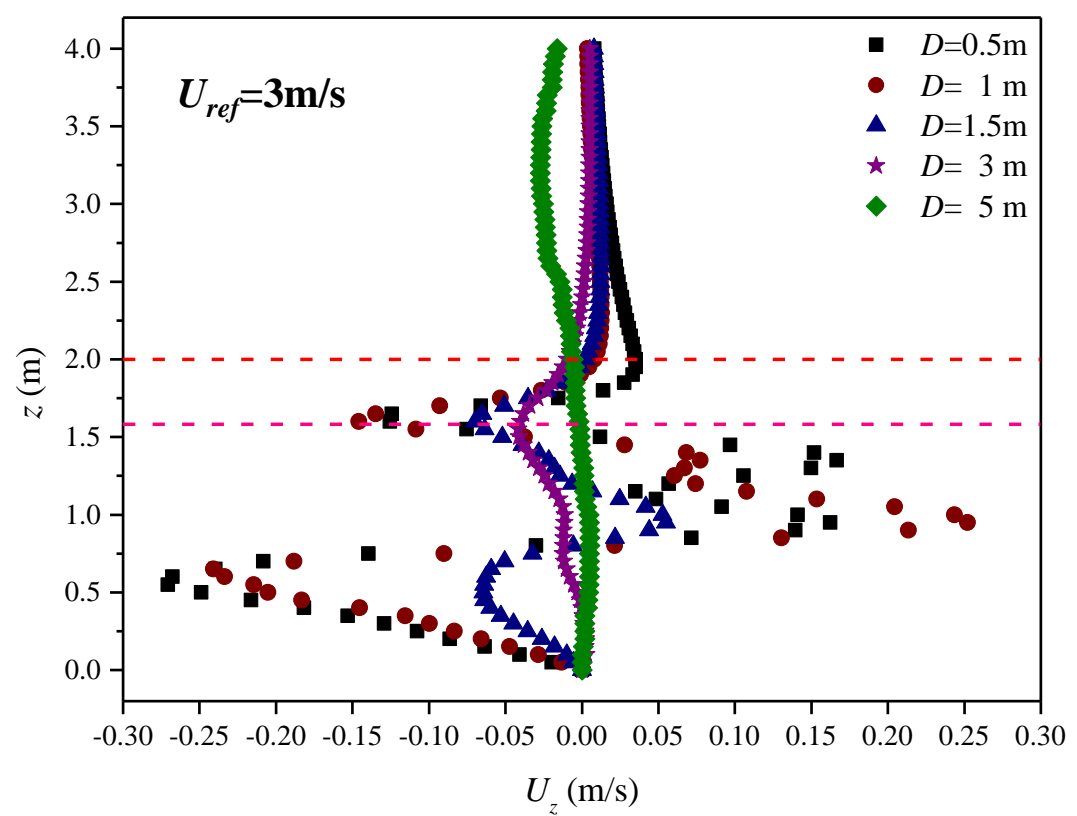

(a)

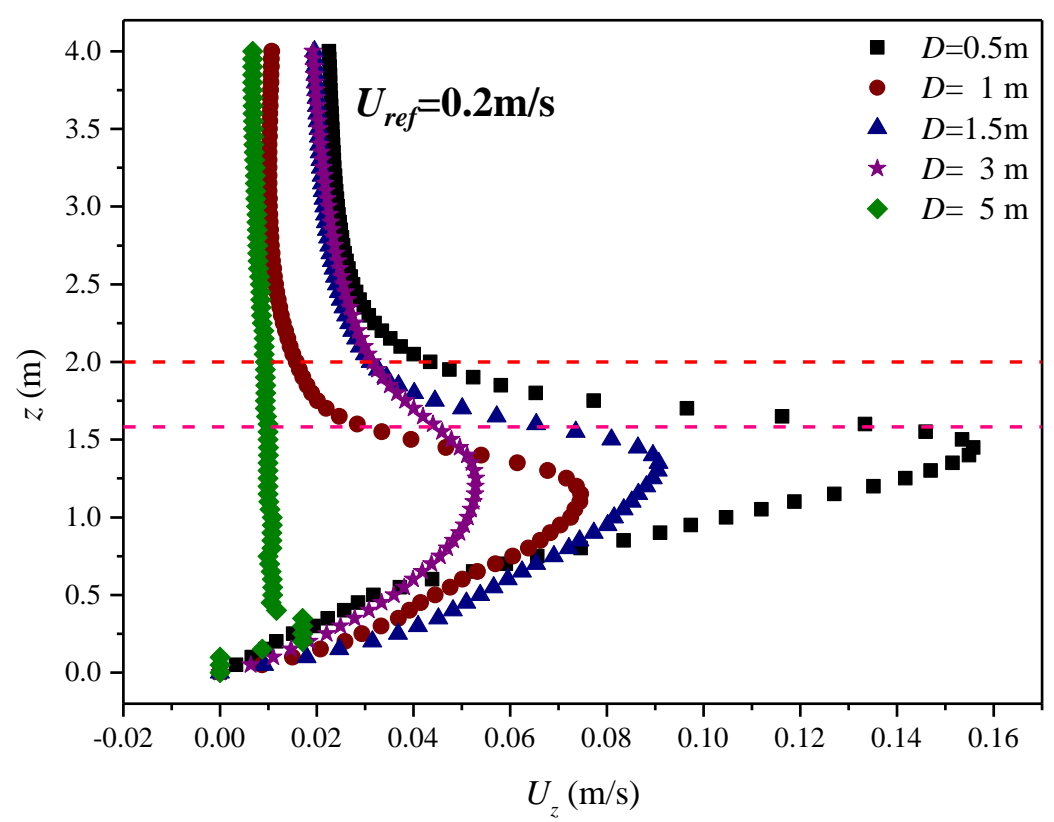

(b)

Fig. 6. Vertical velocity $\left(U_{z}\right)$ at the center line $(x=0, y=0)$ under (a) $U_{r e f}=3 \mathrm{~m} / \mathrm{s}$, (b) $U_{\text {ref }}=0.2 \mathrm{~m} / \mathrm{s}$ 6 

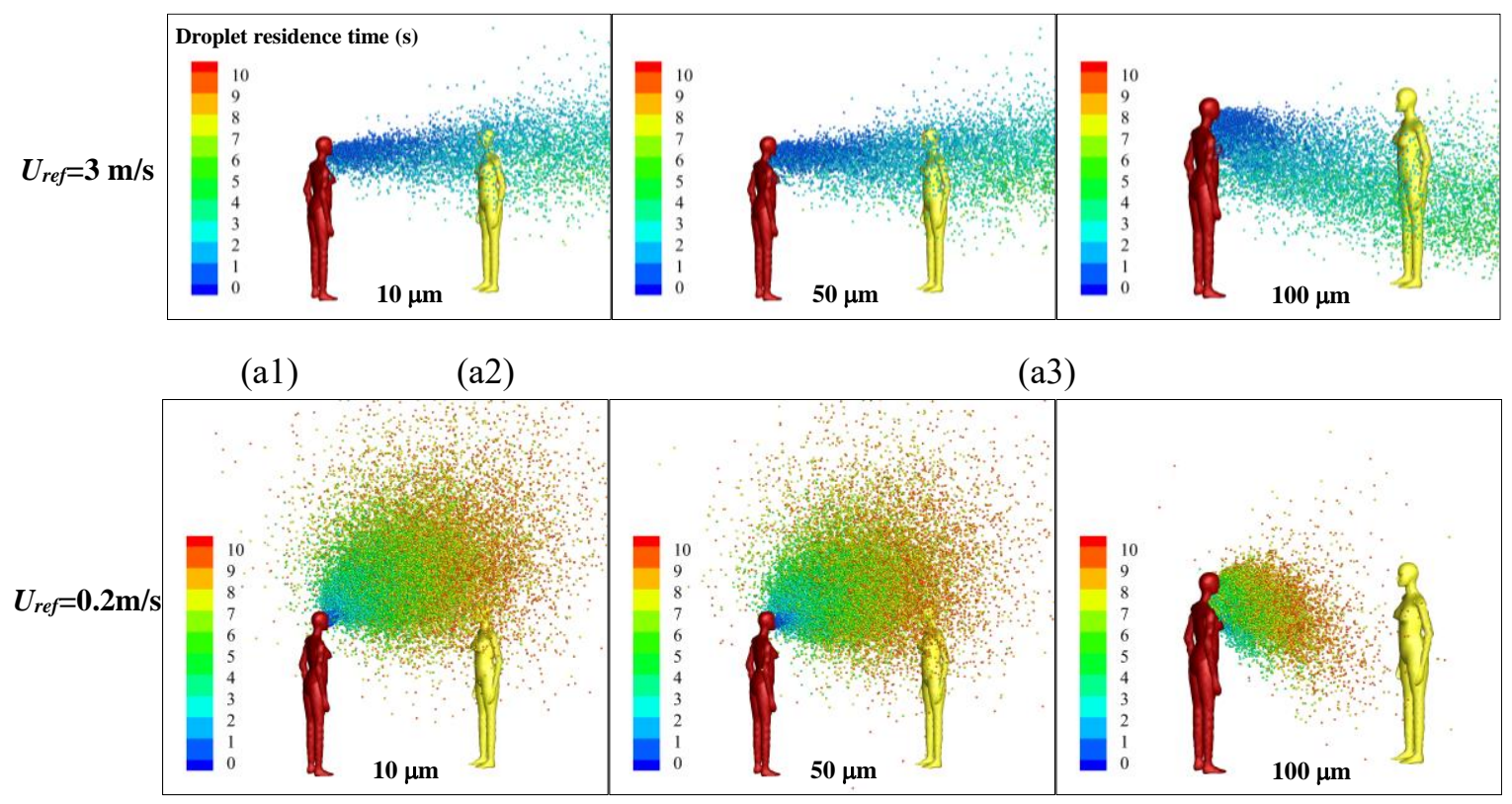

(b1)

(b2)

(b3)

8 Fig. 7. Droplets dispersion $(10 \mu \mathrm{m}, 50 \mu \mathrm{m}$ and $100 \mu \mathrm{m})$ under (a1-a3) $U_{\text {ref }}=3 \mathrm{~m} / \mathrm{s}$ and (b1-b3)

$9 \quad U_{\text {ref }}=0.2 \mathrm{~m} / \mathrm{s}$ at $t=10 \mathrm{~s}$ when $D=1.5 \mathrm{~m}$ and $R H=35 \%$.

10

11

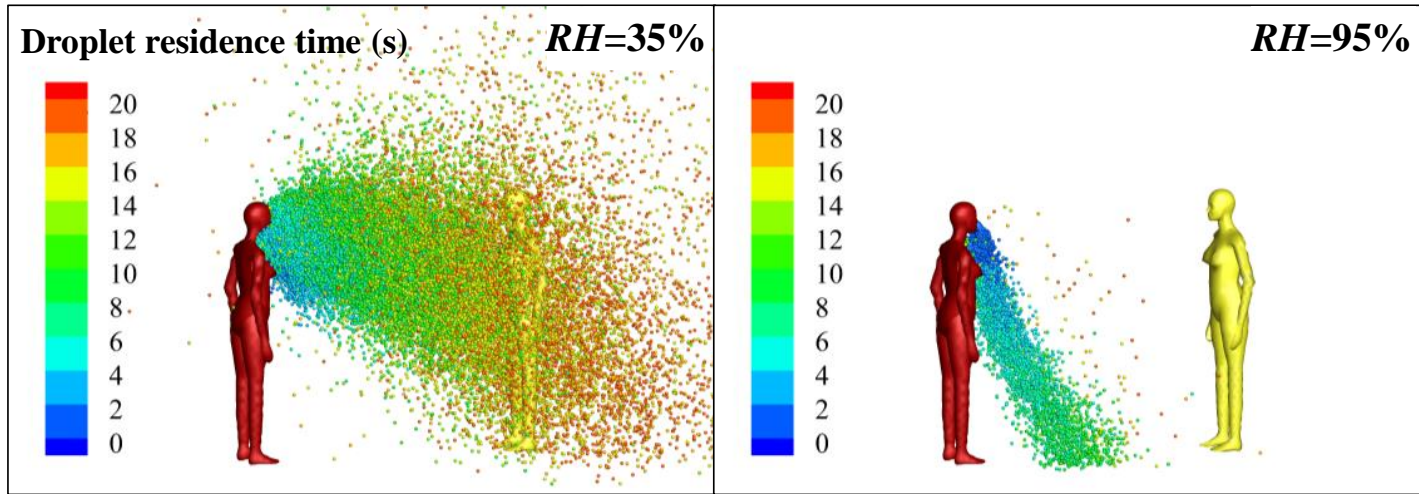

(a)

(b)

12 Fig. 8. Droplets dispersion of $100 \mu \mathrm{m}$ under (a) $R H=35 \%$ and (b) $R H=95 \%$ when $D=1.5 \mathrm{~m}$ and $13 U_{r e f}=0.2 \mathrm{~m} / \mathrm{s}$. 
(a)

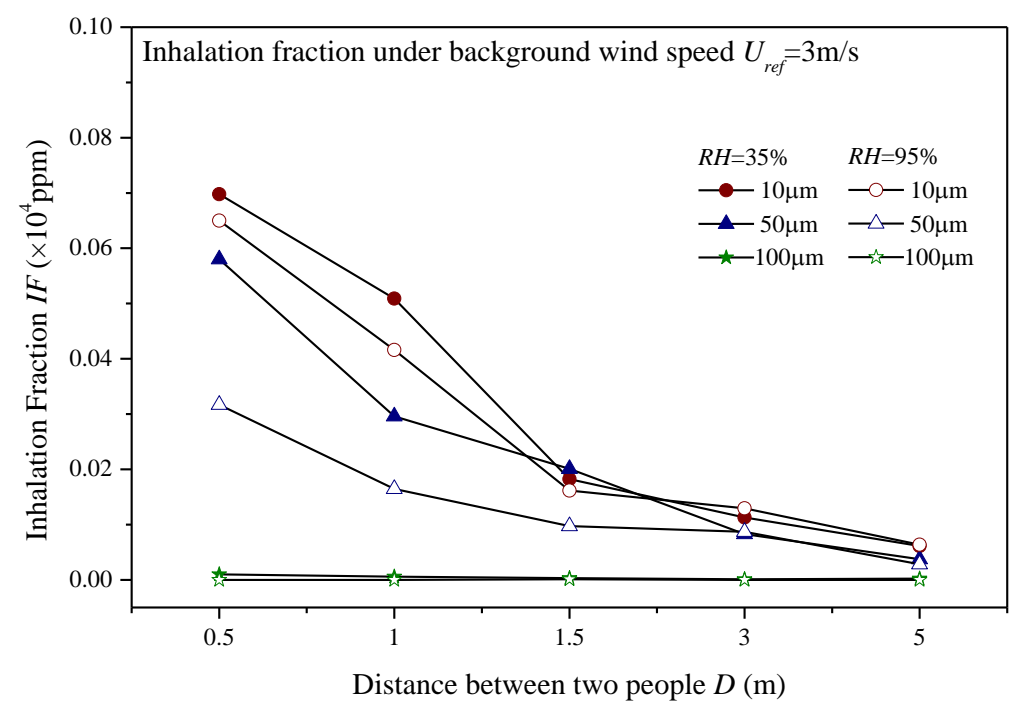

(a)

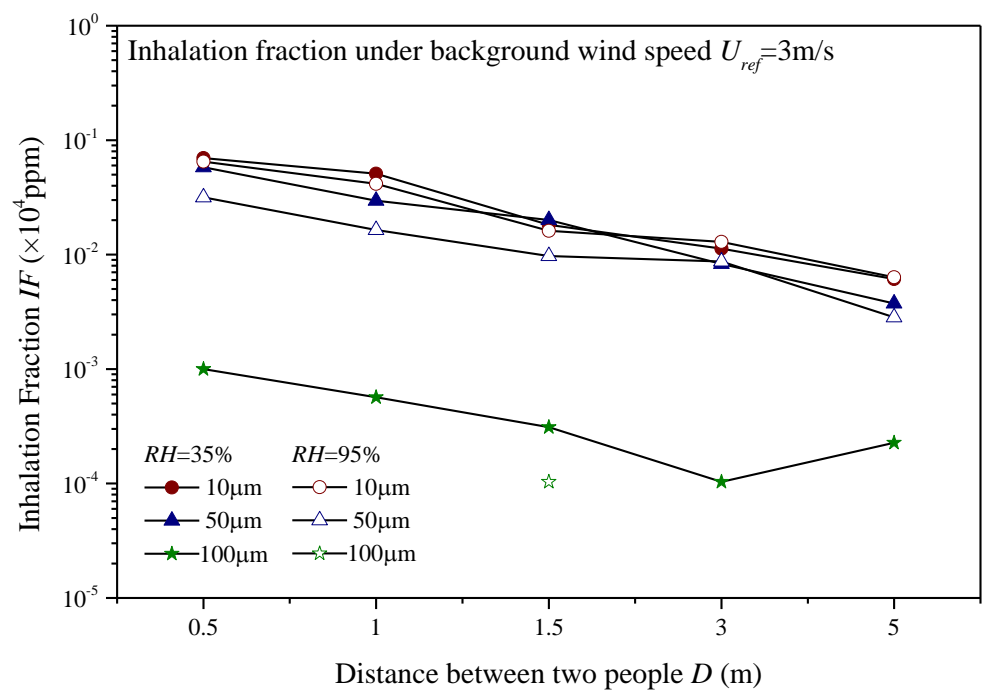

(c)

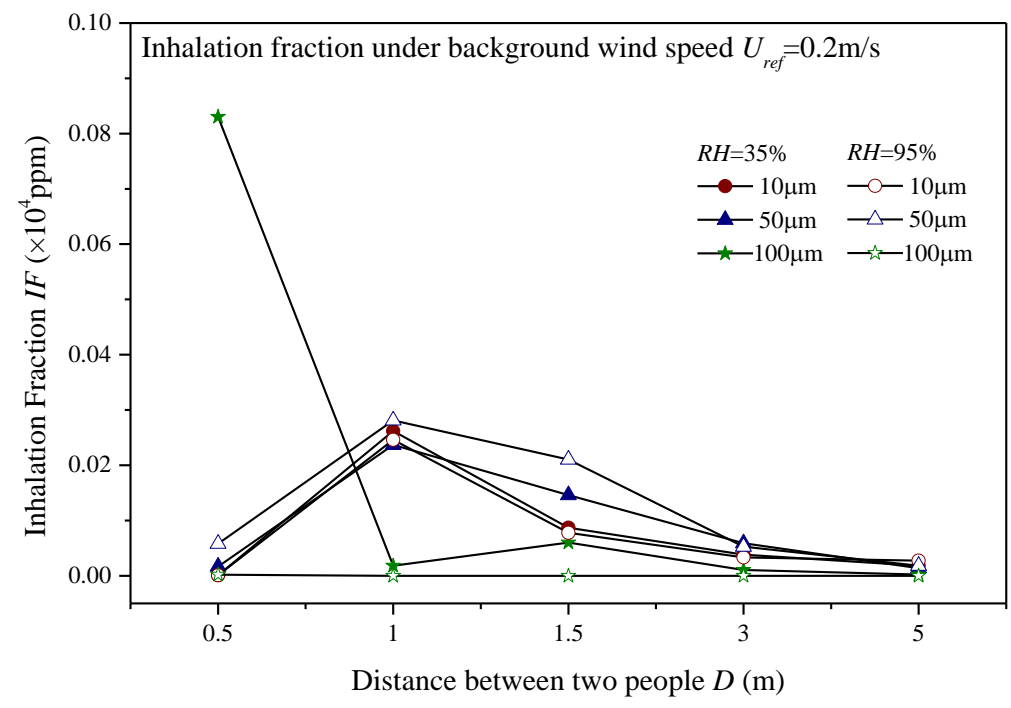

15 Fig. 9. Normalized droplet number inhaled by the susceptible person $(I F)$ under (a,b) $U_{r e f}=3 \mathrm{~m} / \mathrm{s}$ 16 and (c) $U_{\text {ref }}=0.2 \mathrm{~m} / \mathrm{s}$. 

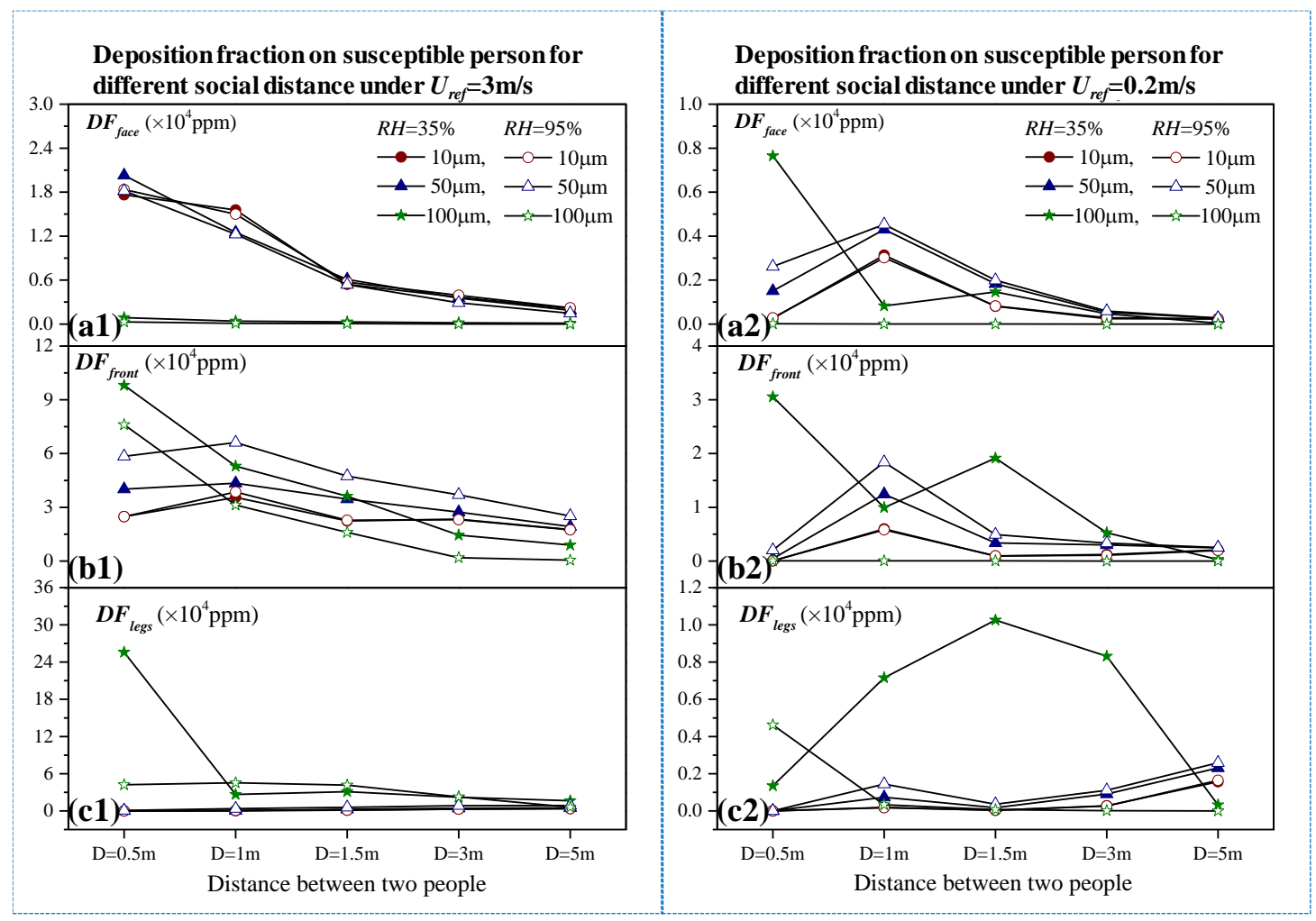

Fig. 10. Normalized droplet number of deposited on different part of the susceptible person under $U_{r e f}=3 \mathrm{~m} / \mathrm{s}$ and $U_{r e f}=0.2 \mathrm{~m} / \mathrm{s}$ : deposition fraction on (a1-2) face $\left(D F_{\text {face }}\right)$; (b1-2) front $\left(D F_{\text {front }}\right)$; (c1- 